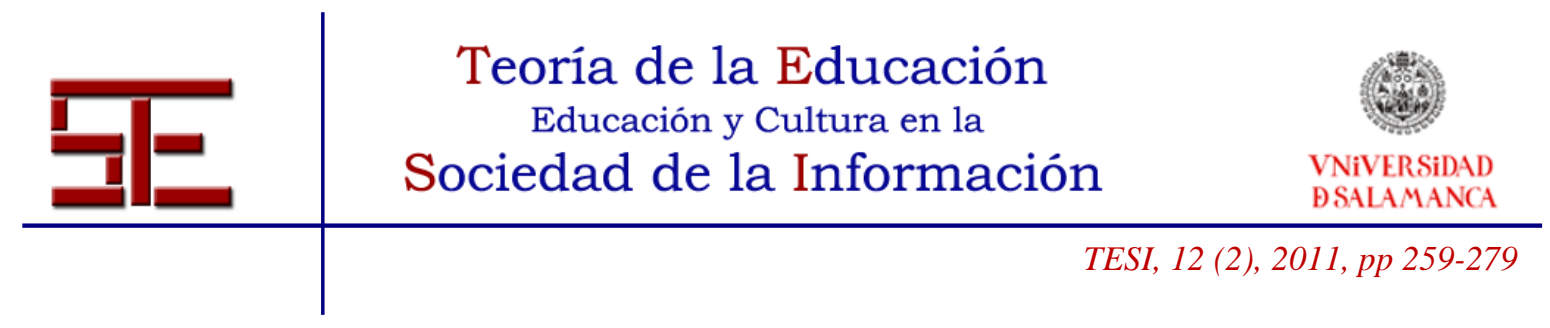

\title{
TABLETAS DIGITALES PARA LA DOCENCIA DEL DIBUJO, DISEÑO Y ARTES PLÁSTICAS
}

Resumen: El uso de dispositivos móviles en la enseñanza está aumentando cada día y las tabletas digitales, de reciente aparición, se perfilan como uno de los instrumentos más flexibles para el ámbito de la educación denominando a la enseñanza sobre este dispositivo como Tablet-Learning. Las posibilidades gráficas de estos dispositivos permiten utilizarlas adecuadamente para la enseñanza de aquellas asignaturas donde la expresión gráfica de las ideas es importante (representación de formas, dibujos artísticos, visualización de modelos tridimensionales, aplicaciones geoespaciales...). En este artículo pretendemos establecer la situación actual de estas tabletas digitales en el mundo educativo y hacer una valoración de las posibilidades de estos dispositivos como herramienta para la docencia del dibujo, diseño y artes plásticas. Analizamos aquellas aplicaciones disponibles para estos dispositivos y que se pueden utilizar en la docencia de estas disciplinas. Dichas aplicaciones se categorizarán de acuerdo a las características de los formatos de trabajo. Dentro de cada una de estas categorías se tratará de encontrar aquellas características que las definen. Se pretende con dicha recopilación que los profesores de estas asignaturas conozcan estas aplicaciones y puedan organizar talleres utilizando estos nuevos dispositivos.

Palabras clave: Aplicaciones informáticas; diseño; educación plástica; innovación tecnológica; recursos didácticos.

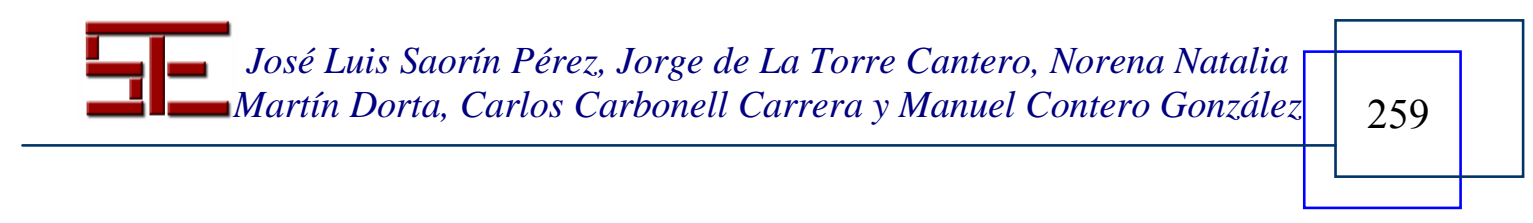




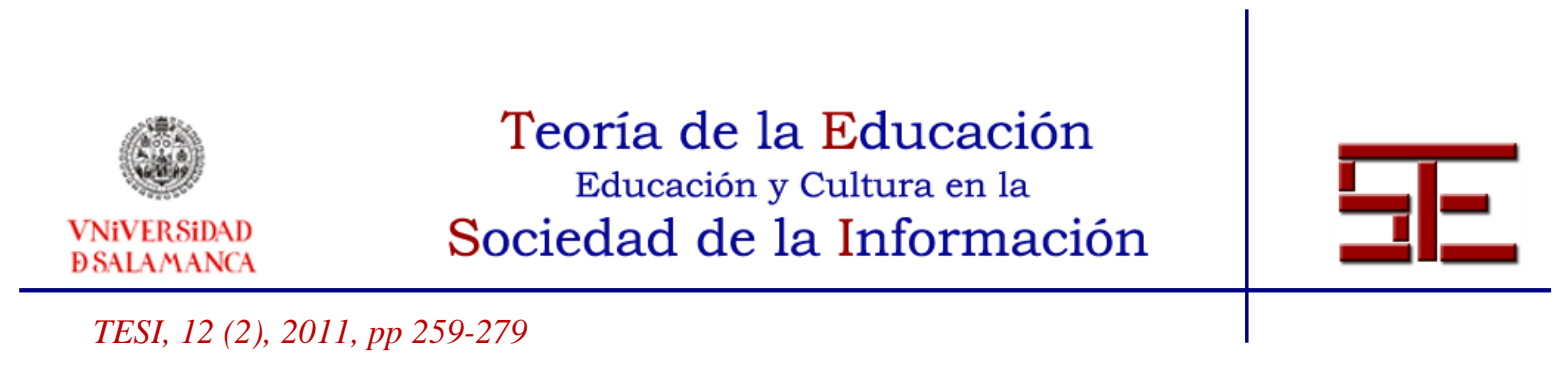

\title{
DIGITAL TABLETS FOR TEACHING DRAWING, DESIGN AND VISUAL ARTS
}

\begin{abstract}
The use of mobile devices in the world of teaching is increasing every day and the newly appeared digital tablets are taking place as the most flexible tools within the field of education. The teaching on this device has been called tablet learning. The graphic possibilities of these devices allow to use them perfectly in the teaching of those subjects where the graphic expression of ideas is important (representation of shapes, artistic drawings, visual display or visualization of 3D models, geospatial applications and so on).

In this article we aim at setting the present situation of these digital tablets within the educational world as well as at evaluating the possibilities of these devices as tools to teach drawing, design and visual arts. We analyze those applications that are available for these devices and can be used in the teaching of these disciplines. Such applications will be classified according to the features of the working patterns. Within each category, we will try to find those features that define it. The purpose of that compilation is to let the teachers, of these knowledge area, know about the set of applications that they use can to organize workshops by using these new devices.
\end{abstract}

Keywords: Art. Education; computer applications; design; digital tablets; learning resources; technological Innovation.

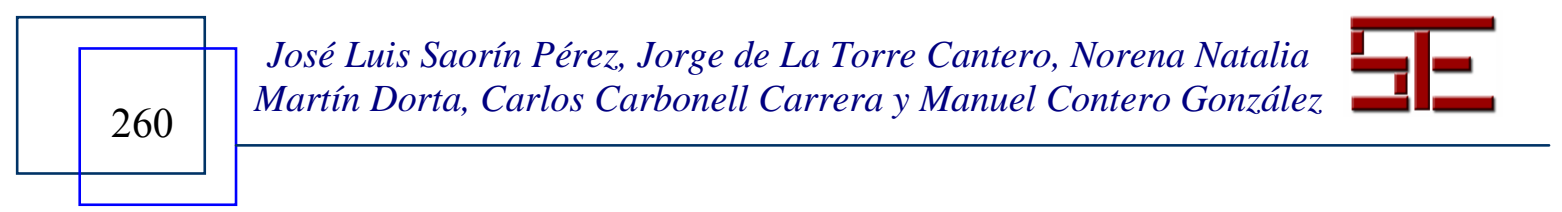




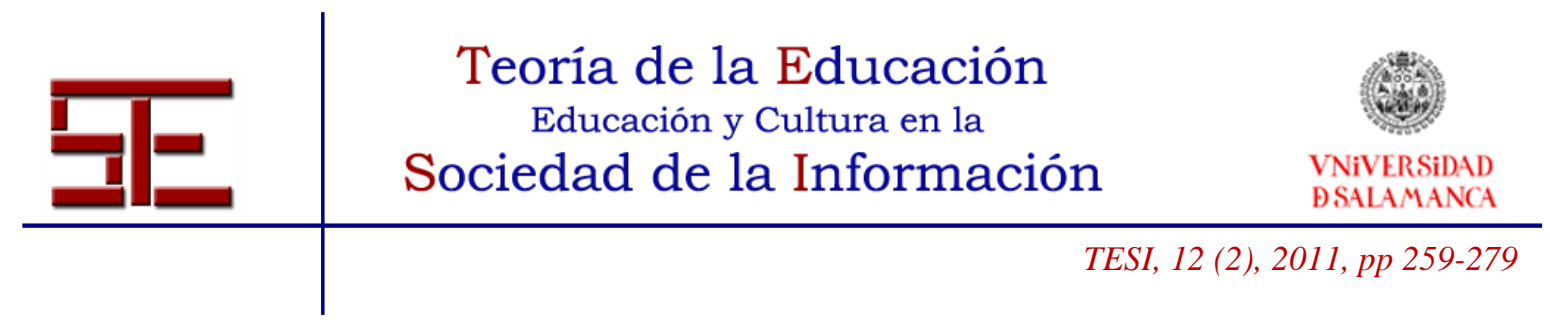

\title{
TABLETAS DIGITALES PARA LA DOCENCIA DEL DIBUJO, DISEÑO Y ARTES PLÁSTICAS ${ }^{1}$
}

Fecha de recepción: 31/03/2011; fecha de aceptación: 11/06/2011; fecha de publicación: 27/07/2011

\author{
José Luis Saorín Pérez \\ jlsaorin@ull.es \\ Universidad de La Laguna \\ Jorge de La Torre Cantero \\ jcantero@ull.es \\ Universidad de La Laguna \\ Norena Natalia Martín Dorta \\ nmartin@ull.es \\ Universidad de La Laguna \\ Carlos Carbonell Carrera \\ ccarbone@ull.es \\ Universidad de La Laguna \\ Manuel Contero González \\ mcontero@dig.upv.es
}

Instituto Universitario de Investigación en Bioingeniería y Tecnología Orientada al Ser Humano

\section{1.- INTRODUCCIÓN}

Recientemente, el Departamento de Proyectos Europeos del Instituto de Tecnologías Educativas (ITE), dependiente del Ministerio de Educación y responsable de la integración de las TIC en la enseñanza, ha presentado el Informe Horizon 2011. Este informe identifica seis nuevos tipos de tecnologías que van a ser de uso generalizado en

\footnotetext{
${ }^{1}$ Este artículo está financiado en parte con fondos procedentes del proyecto: «Mejora del Razonamiento Espacial y Visual mediante Herramientas Tecnológicas Avanzadas» (ESREVIC). Ministerio de Educación, Plan Nacional de I + D + I (2008-2011). Ref. TIN2010-21296-C02-02.
}

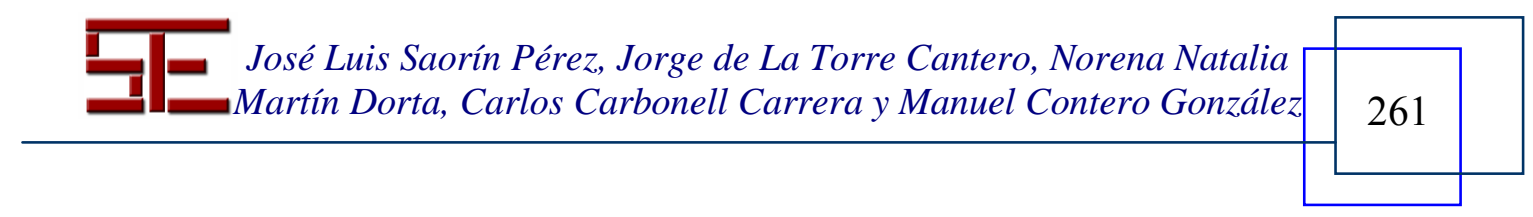




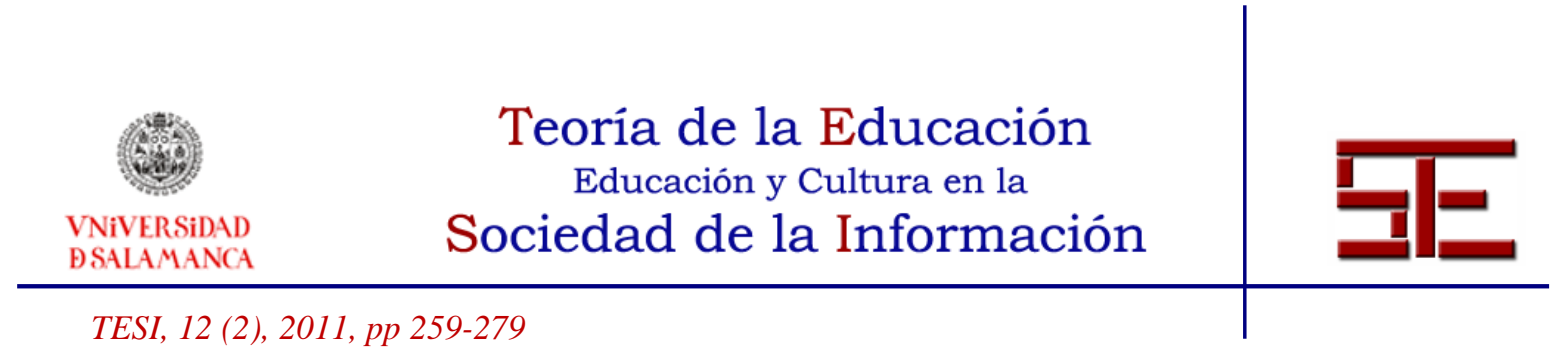

los centros universitarios analizando el impacto que se prevé en la enseñanza, el aprendizaje, la investigación y la expresión creativa.

Entre estos seis nuevos tipos de tecnologías figuran los ebooks, la informática móvil y la informática basada en gestos, tecnologías todas ellas integradas en una Tableta Digital.

Se plantea, por tanto, la necesidad de analizar las posibilidades que ofrece el denominado Tablet Learning en los procesos de digitalización tanto de la enseñanza (elearning) como de contenidos y herramientas en los que están inmersas las instituciones educativas.

Este proceso lleva ya tiempo en marcha, sin que se tenga clara la manera de afrontarlo (Area-Moreira, 2001). Hasta hace unos años, siempre que se hablaba de educación y nuevas tecnologías se pensaba en ordenadores tanto de sobremesa como portátiles y en aplicaciones locales. La popularización de Internet generó un modelo educativo basado en el uso de la web (e-learning). Por otro lado, la aparición de dispositivos móviles táctiles ha creado una corriente de mobile learning (m-learning), que hasta ahora siempre estaba limitada en sus contenidos por el tamaño de las pantallas. Recientemente la irrupción en el mercado de la primera tableta digital táctil realmente operativa (iPad) hace que nos estemos planteando que quizás estos dispositivos, a pesar de tener a día de hoy una penetración muy pequeña, puedan ser utilizados masivamente en educación en un futuro próximo.

Las tabletas digitales, en cierta medida, combinan las ventajas de un ordenador portátil y las de un dispositivo móvil tipo PDA o teléfono. Debido a su reciente aparición y a que existen en el mercado muy pocos modelos operativos, todavía no se han explotado sus capacidades en educación. También es cierto que la implantación de nuevas tecnologías en educación avanza con dificultades ya que necesita de muchos elementos para el buen funcionamiento de este tipo de enseñanza. En cierta medida una docencia que explote estas tecnologías deberá estar apoyada por aulas virtuales, redes wifi, nuevas metodologías docentes, formación adecuada del profesorado y de los estudiantes, aparatos electrónicos actualizados... sin embargo, pensamos que conocer las posibilidades de las tabletas digitales es interesante y permite empezar a diseñar experiencias puntuales, en formato taller, que nos orienten en el modelo docente que se quiera implementar en los centros educativos del futuro.

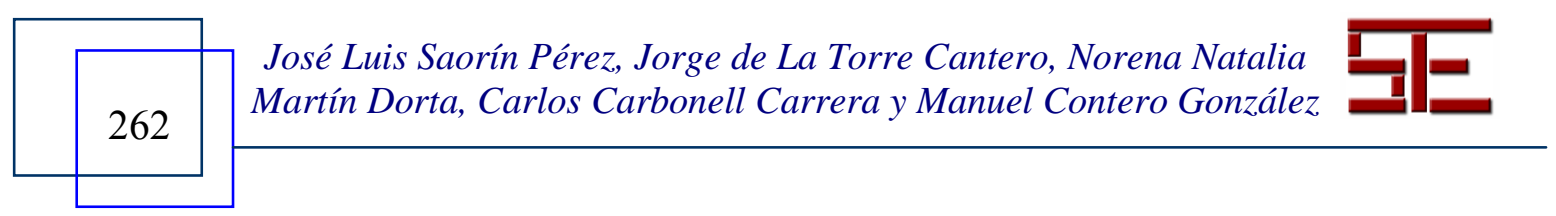




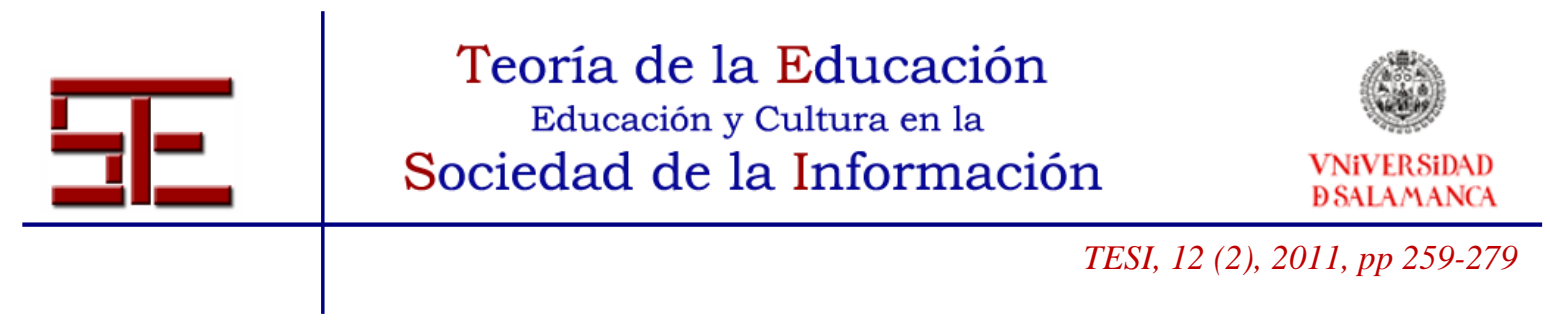

Con la aparición de las Tabletas Digitales con tecnología multitáctil, surge otra forma de interactuar con los softwares gráficos. Movilidad, posibilidades gestuales, interacción tridimensional son nuevos aspectos a analizar en las aplicaciones de dibujo para tabletas. La movilidad y la accesibilidad a los recursos en red de los centros educativos se está incrementando notablemente con la utilización de este tipo de dispositivos. Sus características de peso, tamaño, autonomía de batería, velocidad de encendido y apagado, acceso a red vía wifi, interacción gestual sobre la pantalla táctil, interacción mediante teclado, su gran profusión en aplicaciones específicas a bajo coste y la inmensa facilidad de adquirirlas e instalarlas.... pueden convertirlos en mucho más que un ordenador, mucho más que una colección de libros, música, vídeos, ... un dispositivo de consumo de medios que orientados correctamente con criterios didácticos pueden ejercer un cambio de paradigma en la docencia de las TIC en los sistemas educativos.

\section{2.- ANTECEDENTES}

\section{1.- Tabletas Digitales}

La idea de una tableta digital no es nueva. En 1968 Alan Kay (XEROC-PARC) diseñó una de ellas, denominada Dyanabook (Austin \& Doust, 2007), que nunca llegó a fabricarse a pesar de llegar hasta la fase de prototipo (Figura 1). Esta tableta inicial estaba pensada, ya en esa época, para el uso educacional en niños. Su creador lo describe de la siguiente manera: "Un panel que cubre toda la extensión de la superficie del aparato. Cualquier disposición del teclado que uno desee puede ser mostrada en cualquier parte de la pantalla. Cuatro sensores de deformación montados en las esquinas del panel registrarán la posición de cualquier toque". Es interesante indicar que el creador de este diseño se involucró años más tarde en el proyecto One Laptop per Child (OLPC), que en cierto modo desencadenó la aparición de los denominados netbooks, que se pueden consideran predecesores de las tabletas actuales.
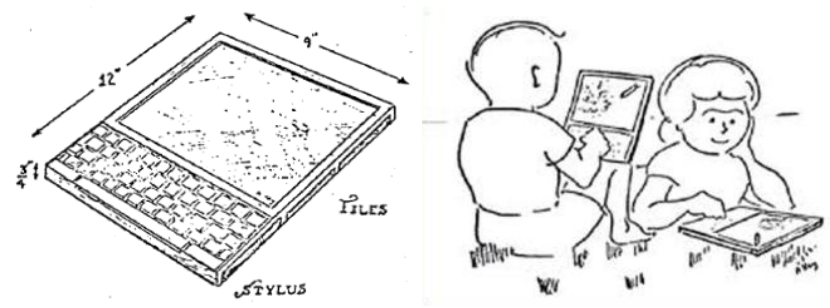

Figura 1: Dynabook.

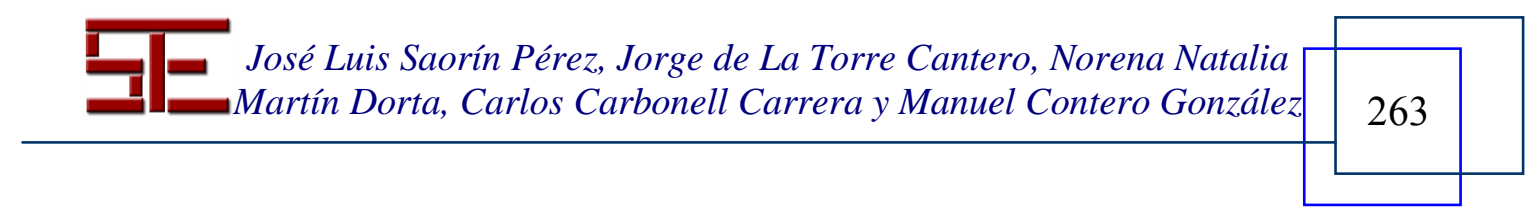




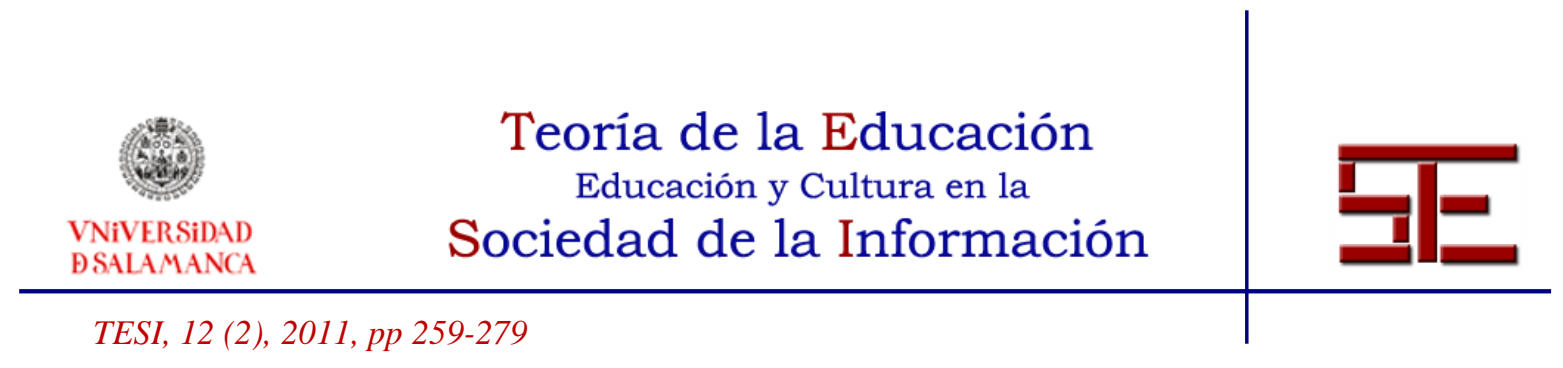

En el año 93 aparece el primer modelo de tableta digital que llegó al mercado. Fue el Apple Message Pad, más conocido como Newton. Este formato luego sería ampliamente adoptado por otros fabricantes, masificando por primera vez la computación portátil en un formato cercano al de los tablets actuales, pues la idea era tener un tamaño pequeño, con pantalla táctil y bajo un sistema operativo móvil desde su nacimiento, como lo eran Newton OS y PenPoint OS. El modelo de Apple nunca llegó a tener éxito, pero sin embargo el desarrollo del software de reconocimiento de escritura realizado para esta tableta se utilizó por la industria de la electrónica para crear un nuevo aparato electrónico denominado Personal Digital Assitant (PDA) (Figura 2).

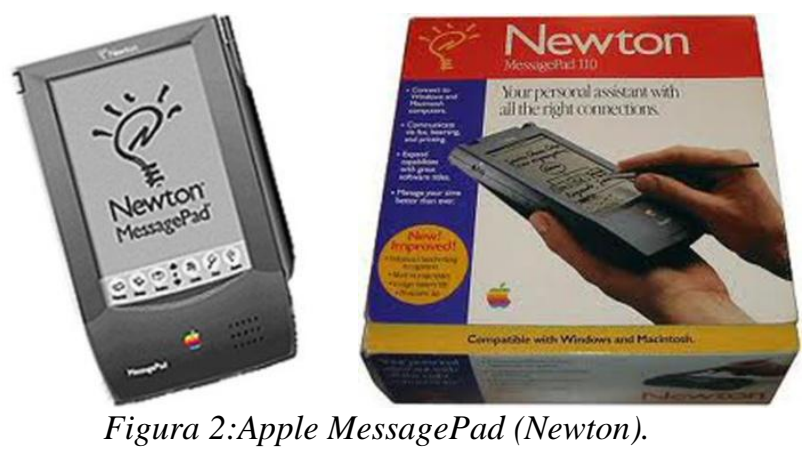

Durante casi una década el mundo de los dispositivos portátiles táctiles estuvo dominado por las PDA donde la empresa Palm era la líder del mercado. En el año 2001 Microsoft presenta en el evento Comdex diversos prototipos de Tablet's Pc, usando el nuevo Windows XP-Tablet PC Edition. Además predijo que en cinco años sería la forma más popular de venta de ordenadores. Esta predicción fue un claro error, el funcionamiento y la experiencia de uso de estos dispositivos no logró convencer a la mayoría de los usuarios, siendo uno de los grandes problemas el sistema operativo que empleaba.

Sin embargo, esta iniciativa de Microsoft popularizó el terminó Tablet PC y sentó las bases de la segunda corriente de tabletas digitales (Figura 3).

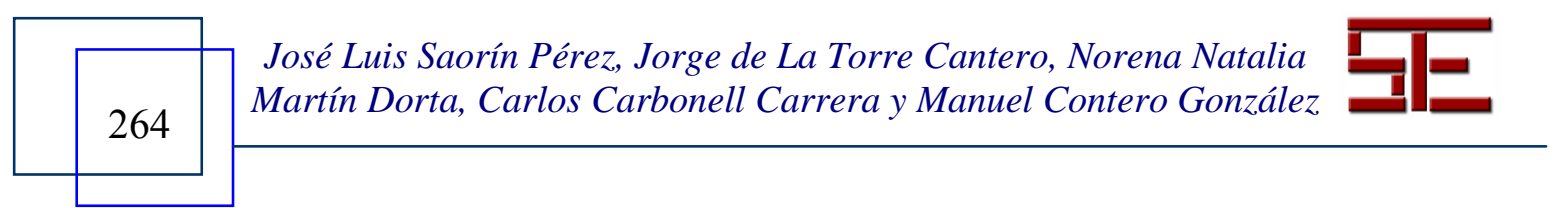



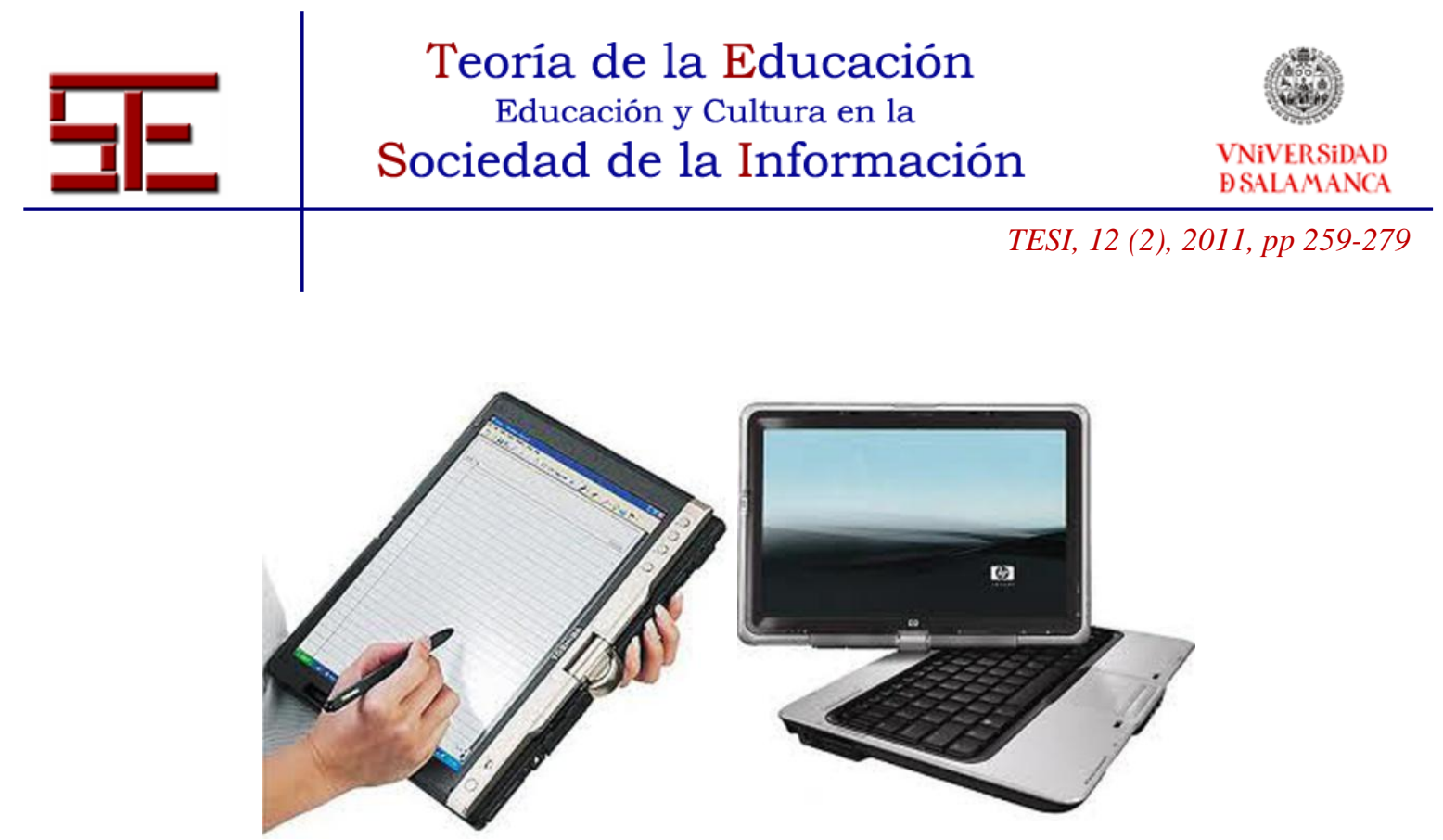

Figura 3: Tablet PC.

A lo largo de los años siguientes aparece una iniciativa muy particular de Nicolás Negroponte denominada One Laptop per Child (OLPC), donde se pretendía fabricar ordenadores portátiles para países del tercer mundo por cien dólares. Esta iniciativa tuvo un éxito relativo, pero sin embargo generó en los países del primer mundo la aparición de un nuevo segmento de equipos, denominados Netbooks, que básicamente eran ordenadores portátiles con poca potencia, pequeño tamaño y bajo precio. La primera empresa que apostó por ellos fue Asus, con el modelo Eee Pc (Figura 4). Esta sorpresa en la industria de la electrónica demostró que a la mayoría de los usuarios no le importaba sacrificar potencia por portabilidad y bajo precio.

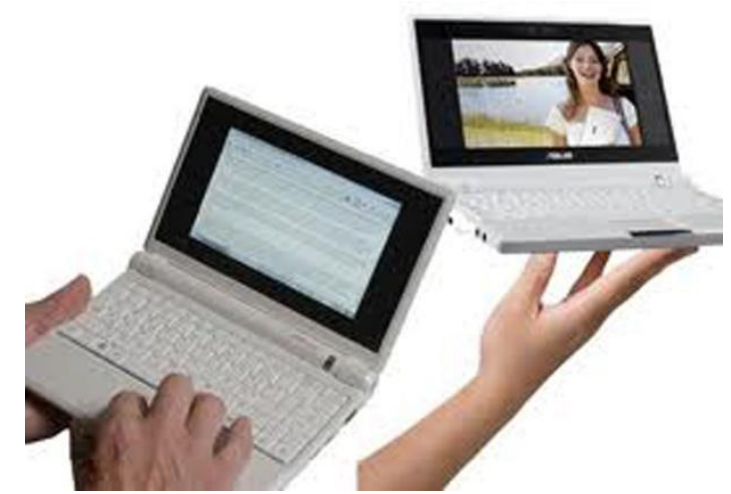

Figura 4: Asus Eee PC

En el año 2010 Apple sorprende de nuevo al mercado poniendo a la venta una tableta digital, el iPad, que aprovechaba la experiencia de la empresa con los dispositivos móviles táctiles que ya tenía en el mercado (el iPhone, el iPod Touch). El éxito de estos

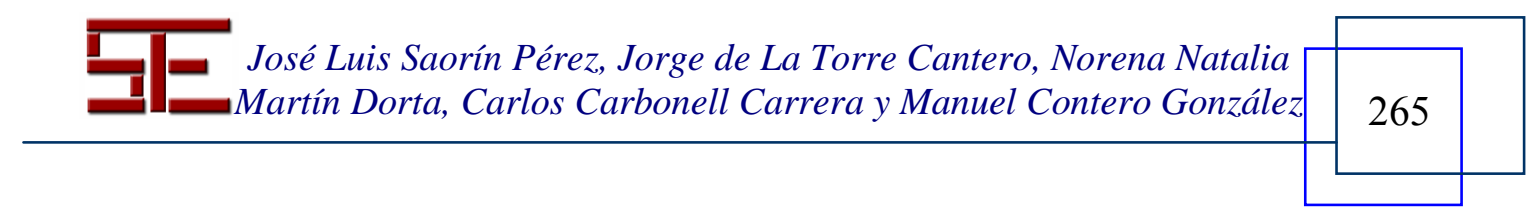




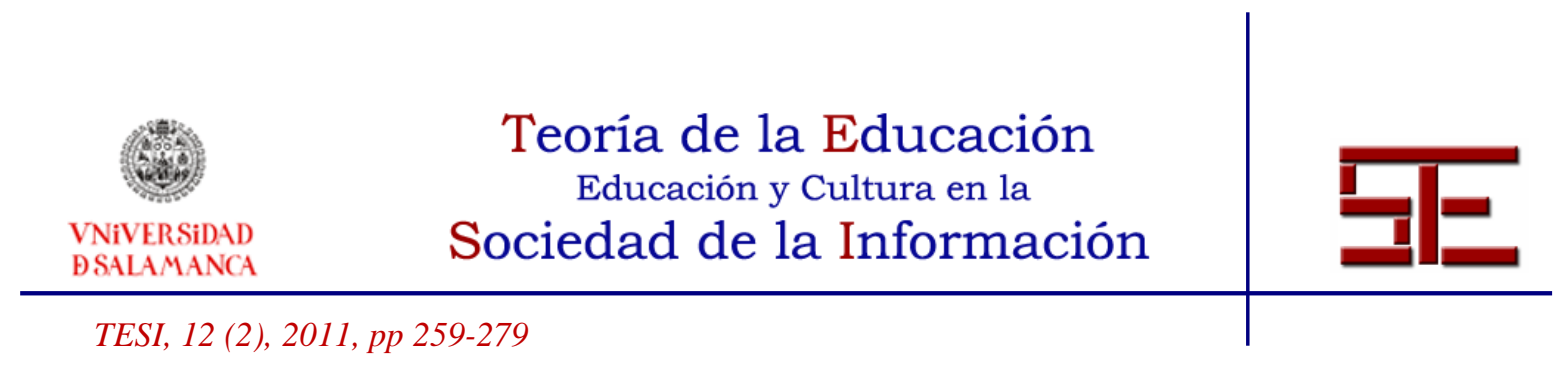

dispositivos no solo se debe a la combinación de hardware y software: la creación de una tienda virtual de aplicaciones (Apple Store) demostró ser un claro acierto al ofrecer al usuario un gran número de aplicaciones para el iPad, iPhone y/o iPod Touch a precios populares (muchas incluso gratuitas) que se descargan por Internet desde el dispositivo. El lanzamiento del Ipad fue un acontecimiento mundial, puesto que por primera vez en muchos años una empresa apostaba por un segmento de mercado que de momento siempre había sido un fracaso. Sin embargo, después de un año, se puede afirmar que las tabletas digitales han creado un nuevo producto que se va a establecer definitivamente. En el año 2010 Apple ha vendido catorce millones de iPads y controla un $85 \%$ del mercado. Una de las consecuencias del asentamiento de las tabletas digitales, es que la venta de ordenadores portátiles, sobre todo Netbooks, ha caído notablemente (Gilbert, 2011).

Para el año 2011 está anunciada la aparición de multitud de nuevas tabletas digitales con sistema operativo Android, Windows 7 y web OS. Esto hará que el número de ventas de tabletas digitales aumente exponencialmente, estando, por lo tanto, en disposición de convertirse en una herramienta educacional a todos los efectos.
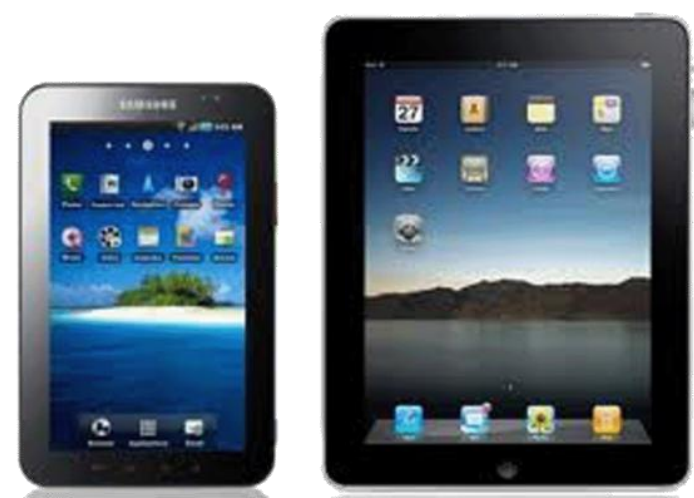

Figura 5: Galaxy Tab (Samsung) e Ipad (Apple).

\section{2.- Digitalización de centros educativos}

Desde hace unos años los centros educativos españoles tienen como objetivo la implantación de las tecnologías de la información y la comunicación (TIC). Se han establecido desde el gobierno central y los diferentes gobiernos autónomos diferentes iniciativas para abordar esa tarea. Por un lado, el Ministerio de Educación y Ciencia a través del ITE (Instituto de Tecnologías Educativas: http://www.ite.educacion.es/) ofrece un portal de apoyo a la incorporación de las TIC al sistema escolar, por otro,

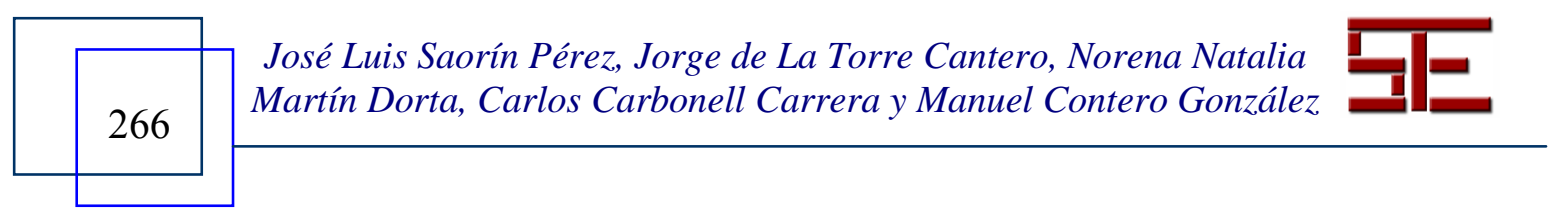




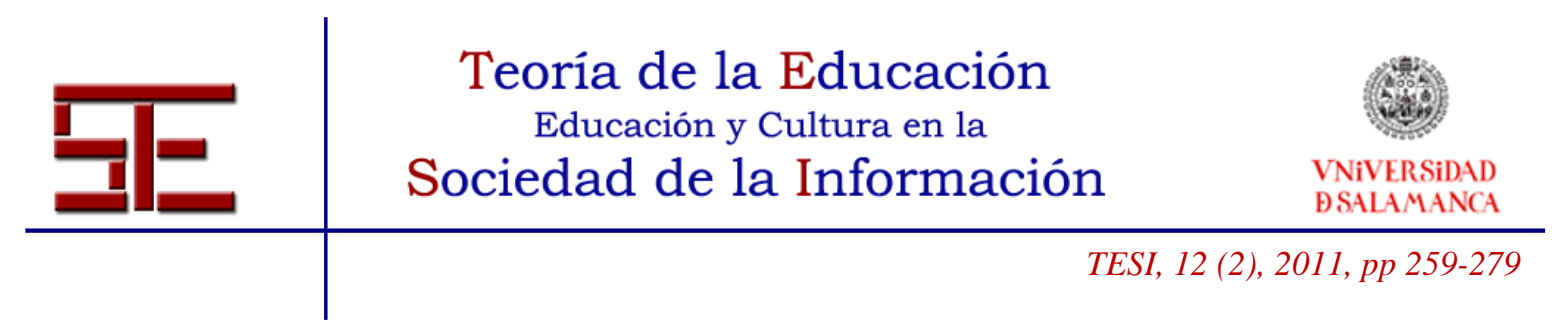

surgen iniciativas autonómicas como el Proyecto Medusa en Canarias (curso 20012002), Averroes en Andalucía, el Programa Ramón y Cajal en Aragón, Plumier en la región de Murcia, el Proyecto SIEGA en Galicia, EducaMadrid en la comunidad madrileña o el Programa Argo en Cataluña (Area-Moreira, 2007).

Recientemente, en el año 2009, el Ministerio de Educación puso en marcha el programa Escuela 2.0 con el objetivo de transformar en aulas digitales los cursos de $5^{\circ}$ y $6^{\circ}$ de primaria y $1^{\circ}$ y $2^{\circ}$ de la ESO. En este programa también se contempla la formación del profesorado y la creación de contenidos educativos digitales.

Las comunidades autónomas desarrollan y complementan el programa escuela 2.0 con distintas iniciativas entre las que cabe destacar la creación de aulas virtuales y de portales educativos digitales destinados a almacenar y poner a disposición de los educadores todos los recursos creados con estos programas. En la comunidad Canaria, por ejemplo, existe el programa Clic escuela 2.0 (2010) que tiene como objetivos declarados: "Este Proyecto pretende que el alumnado sea un usuario digital inteligente, crítico con la información y respetuoso con el contexto digital en el que se relaciona".

Se ha complementado con el programa eco escuela 2.0 ("El propio entorno y la filosofía de trabajo se basa en el modelo WEB 2.0, en el que los usuarios y usuarias gestionan, publican, editan, intercambian toda la información y conocimiento, lejos del modelo tradicional en el que solamente se podía consultar la información en la WEB Web 1.0") que incluye redes sociales, foros, blogs y aulas virtuales que son gestionadas a través del proyecto EVAGD (Gestión Virtual del Aprendizaje de Gestión Distribuida de Canarias).

Lo que queda claro es que desde hace una década se está intentando mediante diferentes estrategias conseguir que la educación española se digitalice (MartínezSánchez, 2003). Se están abordando muchos frentes a la misma vez. Por un lado contenidos, por otro formación, por otro infraestructuras, en un entorno de tecnologías muy cambiantes donde hace una década no existían ni las redes sociales ni los teléfonos inteligentes ni las tabletas digitales, por citar solo algunos casos.

Los centros educativos superiores (universidades e institutos de investigación) tienen sus propios programas de digitalización. Cabe destacar la aparición en casi todas las universidades de los centros de Docencia Virtual, de la progresiva implantación de cañones de video en todas las aulas, del acceso a Internet mediante redes wifi en los

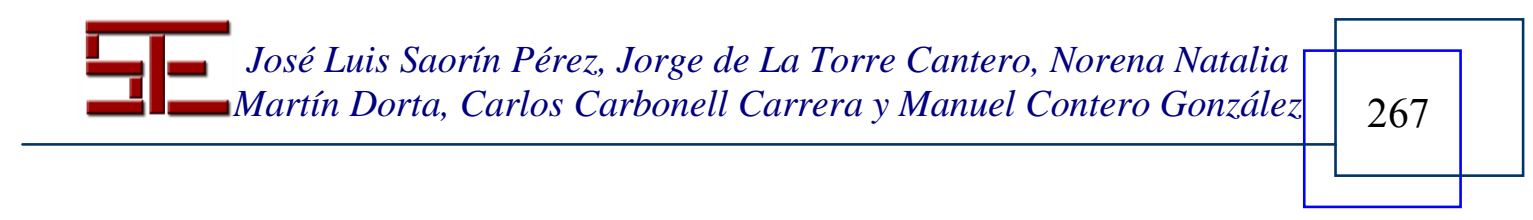




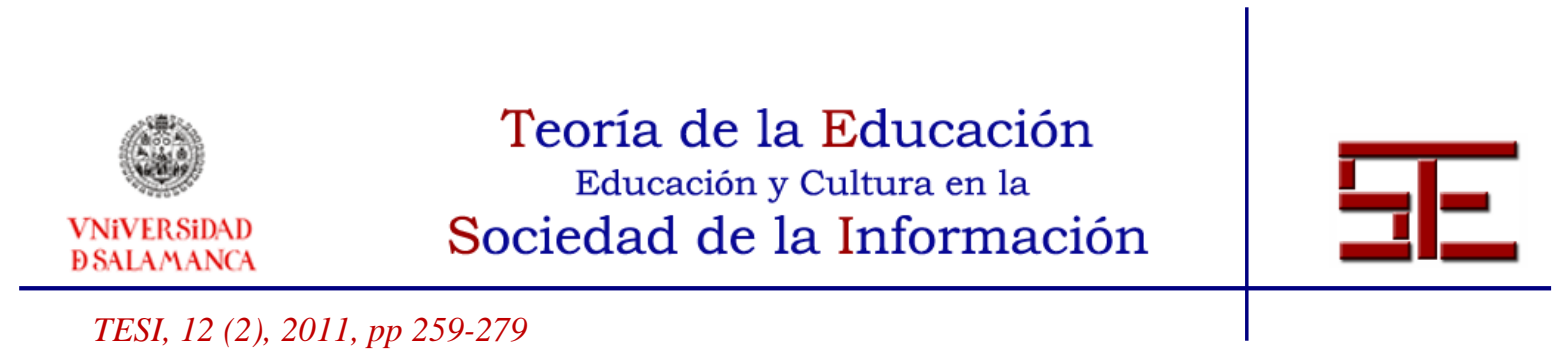

campus universitarios, etc... (Imbernón, Silva \& Guzmán, 2011).

Por ello la situación de los centros educativos en cuanto a la digitalización es muy variable y depende, a veces, de la comunidad autónoma, de la propia iniciativa del centro o de otros factores de difícil cuantificación.

\section{3.- Aprendizaje móvil (mobile learning)}

Las tecnologías de la información y comunicación (TIC) han venido a revolucionar en muchos aspectos la vida del ser humano y el ámbito educativo no ha sido una excepción. El aprendizaje móvil (mobile learning o m-learning) es definido como la impartición de educación y formación por medio de dispositivos móviles, tales como PDAs, iPods, smartphones (teléfonos inteligentes) y teléfonos móviles. Se considera una evolución natural del e-learning o aprendizaje electrónico, diferenciándose de éste en que el uso de la tecnología móvil confiere flexibilidad al aprendizaje, dado que los estudiantes pueden aprender en "cualquier momento y en cualquier lugar".

El m-learning es un concepto nuevo en el ámbito pedagógico del aprendizaje. El primer trabajo publicado que pone su atención en el aprendizaje móvil surge en el año 2000, en la revista Computers \& Education (Sharples, 2000), donde el autor examinó el potencial de los nuevos diseños apoyados en tecnologías móviles que permitieran mejorar los programas de aprendizaje permanente y las oportunidades de educación continua para adultos. Muchas, si no todas, de las ideas planteadas en este trabajo de Sharples siguen evolucionando y son de gran interés en el m-learning hoy en día. Sharples es uno de los investigadores más activos en el campo del aprendizaje móvil.

El grupo DEHAES (Grupo de Investigación en Habilidades Espaciales) de la Universidad de La Laguna ha desarrollado aplicaciones específicas para este tipo de dispositivos dirigidas a la docencia de expresión gráfica (Martín-Dorta, SánchezBerriel \& otros, 2010). Se observa que las pantallas son un elemento limitador, cuando se habla de aplicaciones dirigidas al ámbito del dibujo.

\section{3.- TABLET LEARNING Y SU RELACIÓN CON EL DIBUJO, DISEÑO Y ARTES PLÁSTICAS}

Los conceptos de e-learning (educación basada en la web) y de mobile learning (educación basada en dispositivos móviles) son plenamente aceptados hoy en día. Está

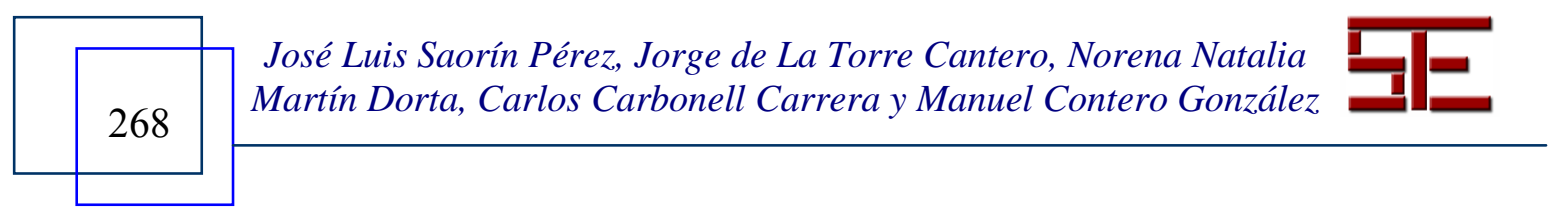




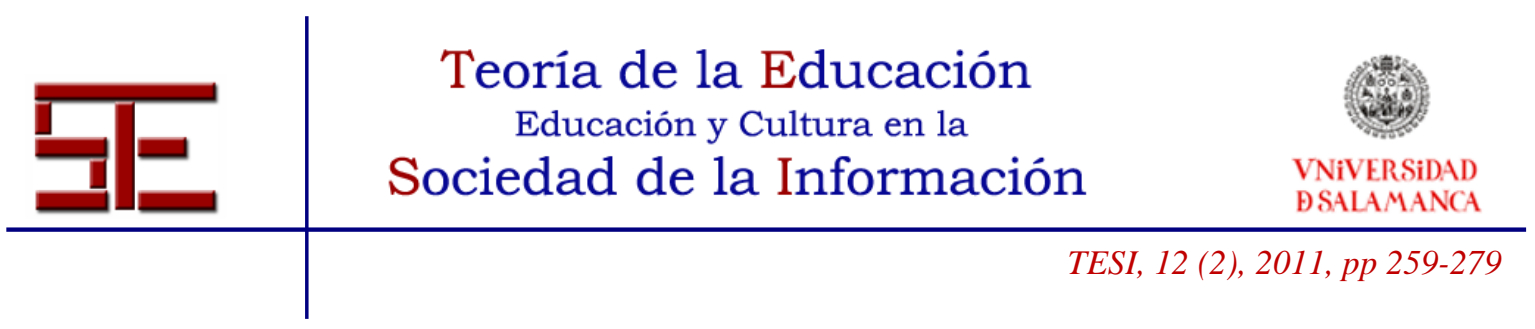

claro que si se quiere digitalizar la educación hay que hacerlo a través de Internet y a través de algún dispositivo tipo ordenador o móvil (Sánchez, Salinas \& Sáenz, 2007; Lu, 2008; Chen \& Chun, 2008; Chris, 2008).

La aparición de las tabletas digitales podría suponer un nuevo hito en los modelos educativos. Las tabletas, con su pantalla cercana a la de un ordenador fijo o portátil, pero con todas las ventajas de movilidad de un teléfono móvil, se perfilan como la piedra angular que puede crear un nuevo modelo formativo que denominamos "tabletlearning". Modelo que podría combinar las ventajas mencionadas y permitir su introducción en los centros educativos de una manera más natural y menos forzada que como se ha hecho hasta ahora.

Las tabletas digitales que están apareciendo en el mercado no son sólo hardware, sino que están complementadas con una tienda de aplicaciones en red. La existencia de estas tiendas de aplicaciones, con programas muy baratos, disponibles y actualizables en red, el encendido casi automático de estos dispositivos y otras características hacen de estos aparatos un recurso educativo similar en manejabilidad a un libro actual, pero con mayores posibilidades.

En estos últimos años, en el ámbito del dibujo se ha adoptado el uso de ordenadores como herramienta fundamental. Se incluyen dentro de este ámbito áreas de dibujo técnico y artístico. Aplicaciones como Auotcad, Solidwords, CorelDraw... son populares en niveles universitarios y a veces en niveles de bachiller. Incluso los libros de texto incluyen temas específicos de aplicaciones CAD (Computer Aided Design) dentro de sus contenidos. Muchas de estas aplicaciones están disponibles en el iPad, aunque se echan de menos algunas muy utilizadas como SketchUp.

La expresión gráfica tiene una interfaz natural en las tabletas. El uso del dibujo a mano alzada, muy utilizado en la docencia clásica, queda relegado a casi nada con las nuevas aplicaciones basadas en el entorno Windows más ratón. Ésta es la razón por la que muchos profesionales del dibujo utilizan digitalizadoras (tipo WACOM) para realizar su trabajo. El tablet PC de Microsoft fue un intento serio de cambiar esta interfaz, y manejar las aplicaciones a través de un lápiz electrónico. La aparición de las tabletas digitales puede significar la fusión del ordenador y la tableta digitalizadora en un mismo dispositivo. Este aspecto, unido al hecho de disponer de aplicaciones específicas en red, hacen que las tabletas digitales se perfilen como un instrumento fundamental a la hora de impartir docencia en asignaturas con fuerte carga de creación y manejo de elementos

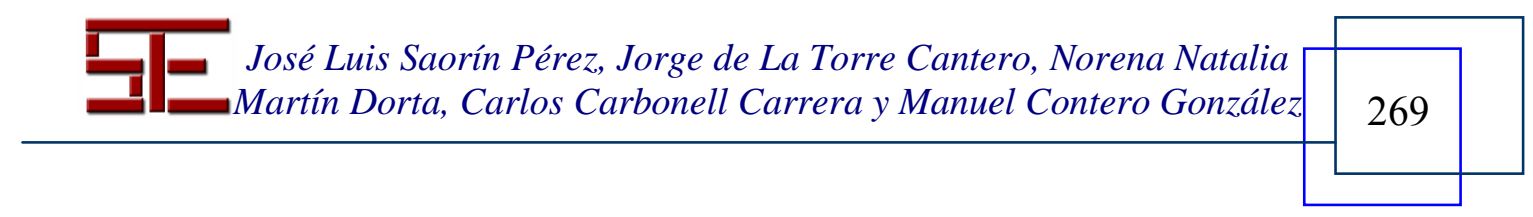




\begin{tabular}{c} 
Teoria de la Educación \\
Educación y Cultura en la \\
$\begin{array}{c}\text { VNiVERSIDAD } \\
\text { BSALAMANCA }\end{array}$ \\
\hline TESI, 12 (2), 2011, pp 259-279
\end{tabular}

visuales. Por ello es importante conocer qué aplicaciones hay disponibles y sus características principales.

\section{1.- Aplicaciones para Tabletas}

La clasificación que se presenta se ha realizado sólo para iPad por ser el dispositivo de mayor implantación y cuya tienda de aplicaciones está actualmente más desarrollada (Tabla 1).

\begin{tabular}{|c|c|c|}
\hline \multicolumn{3}{|c|}{ Aplicaciones Gráficas para iPad de utilidad en Dibujo, Diseño y Artes Plásticas } \\
\hline CATEGORÍA & DESCRIPCIÓN & $\begin{array}{l}\text { UTILIDAD EN } \\
\text { ASIGNATURAS }\end{array}$ \\
\hline $\begin{array}{l}\text { VISUALIZADORES DE } \\
\text { MODELOS 3D }\end{array}$ & $\begin{array}{l}\text { Aplicaciones que permiten visualizar modelos 3D e } \\
\text { interactuar con ellos (rotarlos, zoom, ...) similares a } \\
\text { aplicaciones como eDrawing, Reviever o Acrobat 3D. }\end{array}$ & $\begin{array}{l}\text { Asignaturas donde el manejo del } \\
\text { volumen sea importante } \\
\text { (escultura, } \\
\text { arquitectura, mapas...) }\end{array}$ \\
\hline MODELADORES 3D & $\begin{array}{l}\text { Aplicaciones que permiten crear modelos } 3 D \text { desde } \\
\text { cero. Entre éstos distinguimos los modeladores } \\
\text { "orgánicos", que permiten crearlos como si } \\
\text { trabajáramos con barro (similares a Zbrush o a } \\
\text { Autodesk Mudbox) orientados a áreas creativas y los } \\
\text { modeladores de caras. }\end{array}$ & $\begin{array}{l}\text { Asignaturas donde la creación de } \\
\text { objetos en 3D sea importante } \\
\text { (Diseño, } \\
\text { arquitectura...) }\end{array}$ \\
\hline DIBUJO VECTORIAL & $\begin{array}{l}\text { Aplicaciones que trabajan con imágenes vectoriales } \\
\text { formadas por objetos geométricos independientes } \\
\text { (segmentos, polígonos, arcos, etc.), cada uno de } \\
\text { ellos definido por distintos atributos matemáticos de } \\
\text { forma, de posición, de color, etc. (similares a } \\
\text { CorelDraw o Adobe llustrator) }\end{array}$ & $\begin{array}{l}\text { Asignaturas orientadas al diseño } \\
\text { gráfico editorial. }\end{array}$ \\
\hline DIBUJO RASTER & $\begin{array}{l}\text { Aplicaciones que trabajan con imágenes rasterizadas, } \\
\text { también llamadas mapas de bits, imágenes } \\
\text { matriciales o bitmaps, a las que solemos llamar fotos } \\
\text { y que podemos generar mediante cámaras digitales, } \\
\text { móviles o escaners y que mediante estas } \\
\text { aplicaciones podremos editar de manera similar a } \\
\text { aplicaciones tan populares como Photoshop. }\end{array}$ & $\begin{array}{l}\text { Asignaturas orientadas a edición } \\
\text { de imágenes fijas }\end{array}$ \\
\hline
\end{tabular}

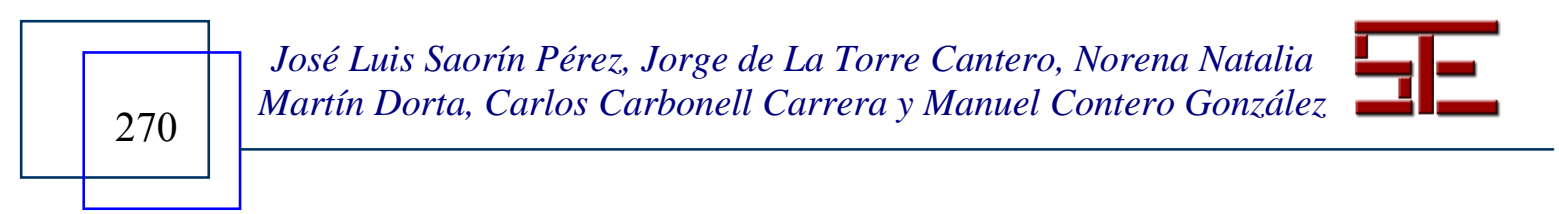



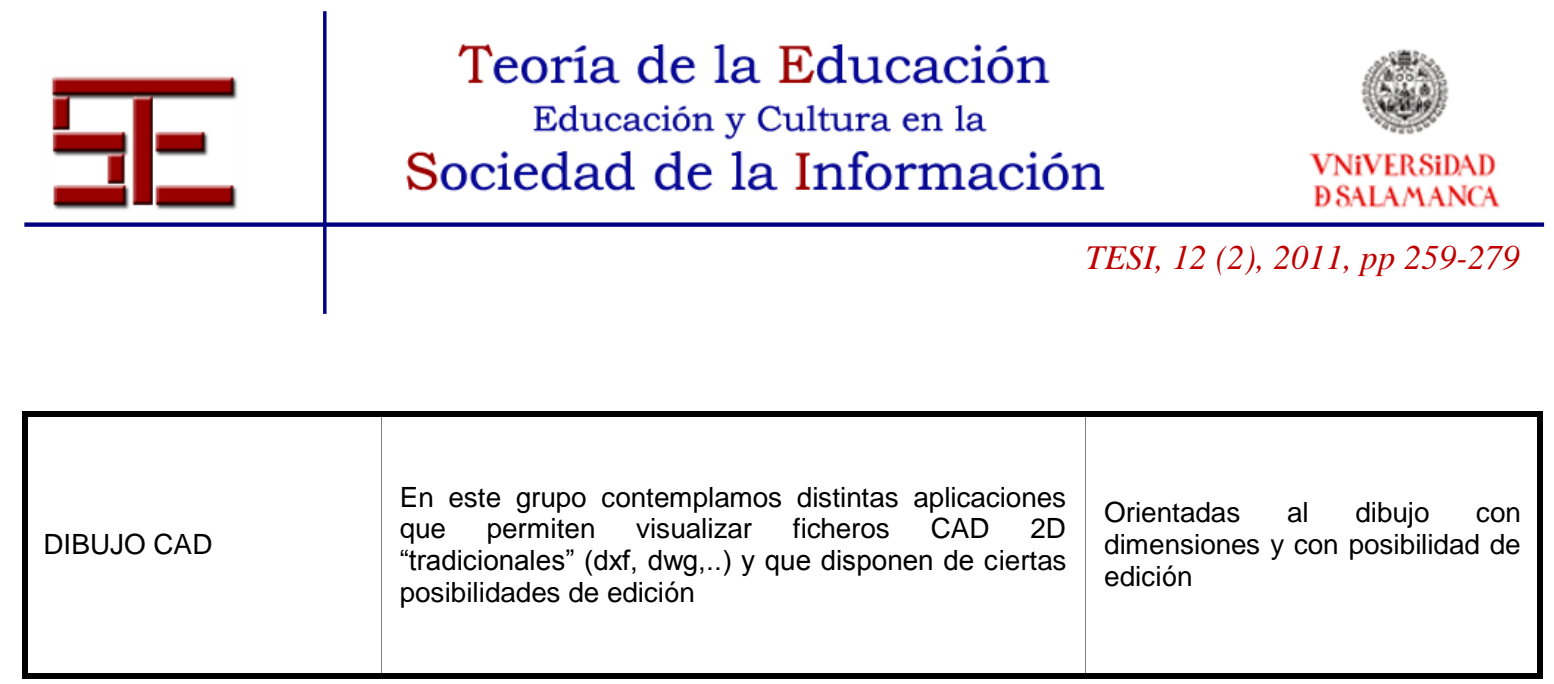

Tabla 1. Aplicaciones gráficas para Ipad de utilidad en Dibujo, Diseño y Artes Plásticas.

Debido a que las aplicaciones analizadas corresponden a diferentes categorías hemos establecido unos parámetros que pensamos que pueden ser de interés de forma general en todas ellas (Tabla 2).

\begin{tabular}{|c|c|}
\hline \multicolumn{2}{|c|}{ Parámetros a analizar de las aplicaciones estudiadas: } \\
\hline PARÁMETROS & DESCRIPCIÓN \\
\hline PRECIO & Analizamos el precio de la aplicación \\
\hline VERSIÓN LITE & Analizamos si se dispone de versión reducida (lite) para poder probarla.. \\
\hline POSIBILIDADES DE EDICIÓN & Analizamos si hay posibilidades de modificación (edición). \\
\hline TRABAJO CON CAPAS & Analizamos si la aplicación permite trabajar con capas. \\
\hline FICHEROS QUE SOPORTAN & $\begin{array}{l}\text { Analizamos los tipos de formatos que admiten las aplicaciones. Esto nos permite } \\
\text { asociarlos a las categorías de aplicaciones que ya conocemos en PC o Mac }\end{array}$ \\
\hline $\begin{array}{l}\text { POSIBILIDADES } \\
\text { ALMACENAR FICHEROS }\end{array}$ & $\begin{array}{l}\text { Analizamos si es posible almacenar los ficheros en la aplicación (dentro del Tablet) } \\
\text { o si es necesario tener espacios en entornos ajenos al Tablet (google docs, dropbox, } \\
\text { skydrive,... }\end{array}$ \\
\hline OBSERVACIONES & $\begin{array}{l}\text { Incluimos en observaciones, comentarios sobre alguna característica particular de la } \\
\text { aplicación. }\end{array}$ \\
\hline
\end{tabular}

Tabla 2: Parámetros a analizar de las aplicaciones estudiadas.

\subsection{1.- Visualizadores de Modelos 3D}

Aplicaciones que permiten visualizar modelos 3D e interactuar con ellos (rotarlos, zoom...), similares a aplicaciones como eDrawing, Design Review o Acrobat 3D (Tabla $3)$.

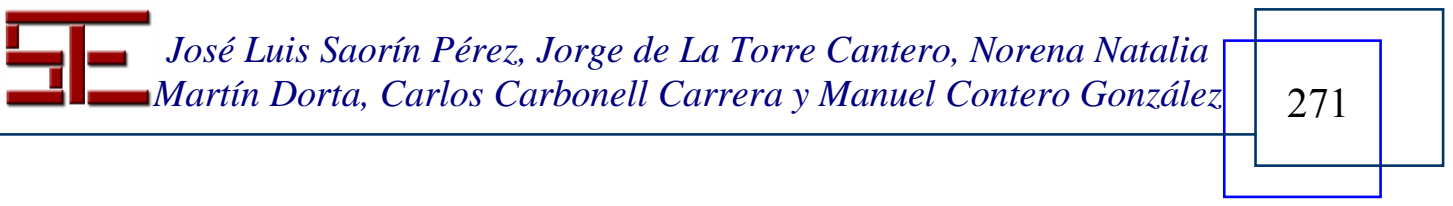




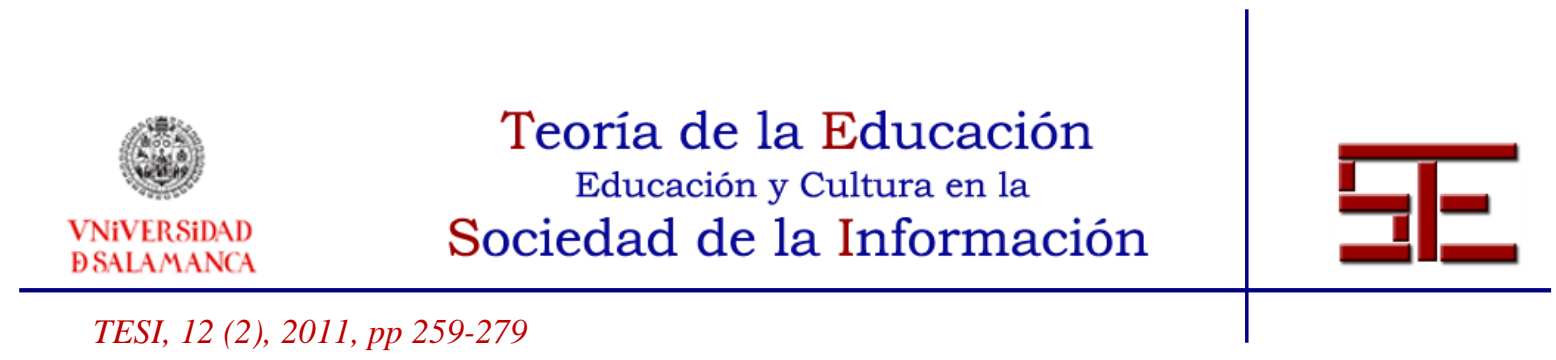

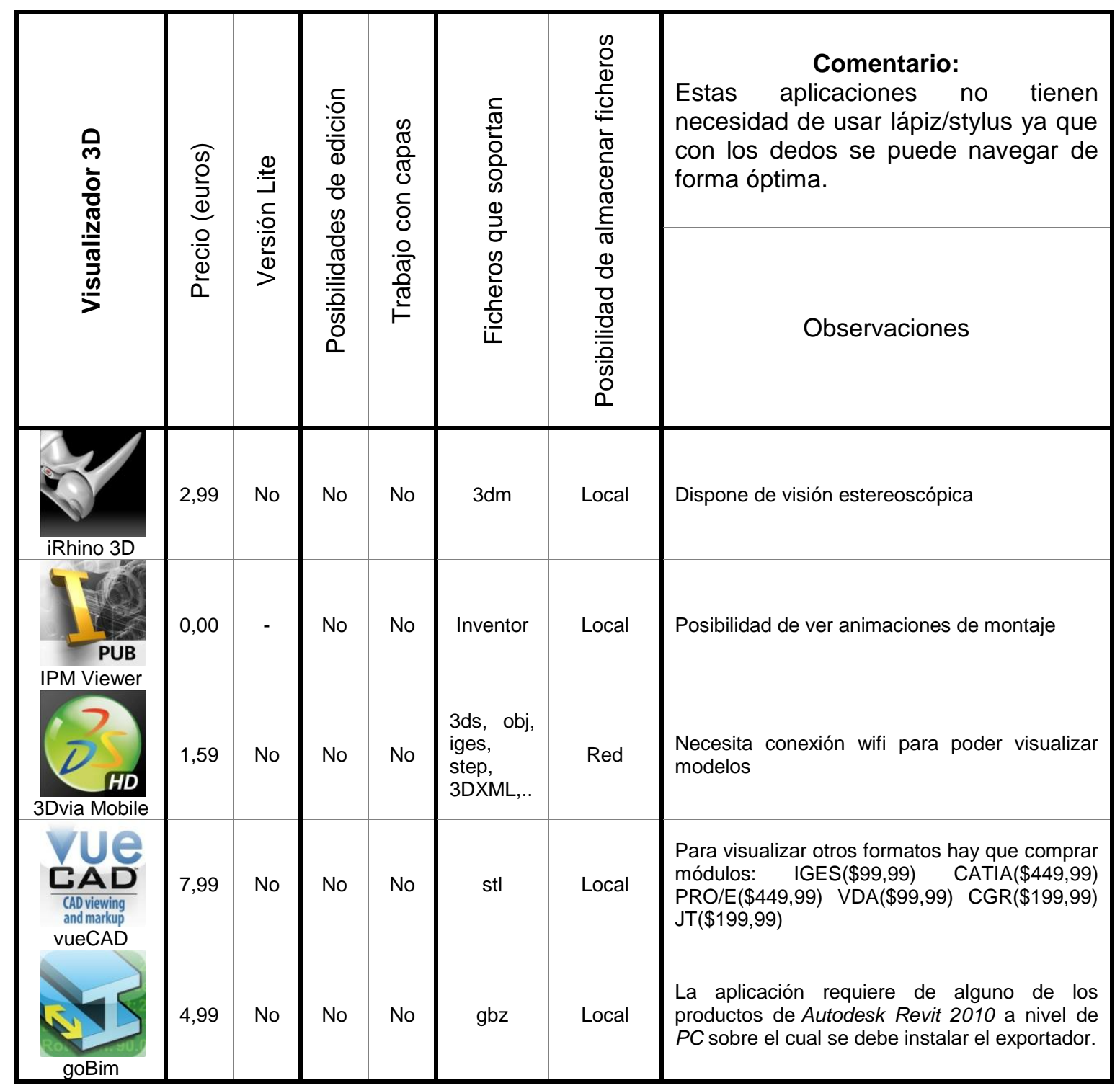

Tabla 3: Visualizador 3D

\subsection{2.- Visualizadores de Modelos 3D}

Aplicaciones que permiten crear modelos 3D desde cero. Entre éstos distinguimos los modeladores "orgánicos", que permiten crearlos como si trabajáramos con barro

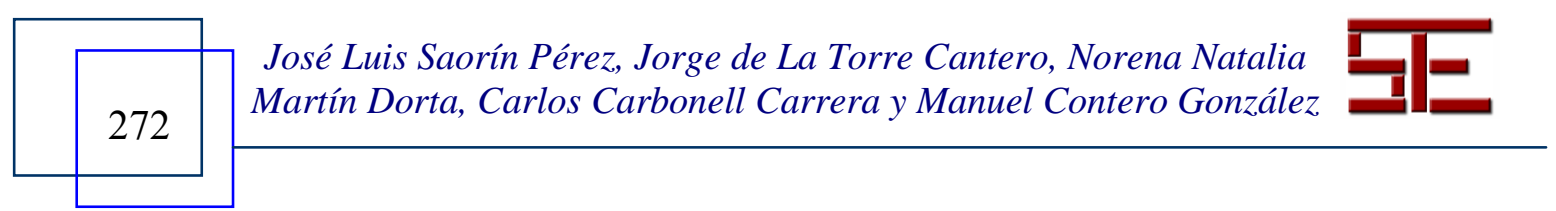




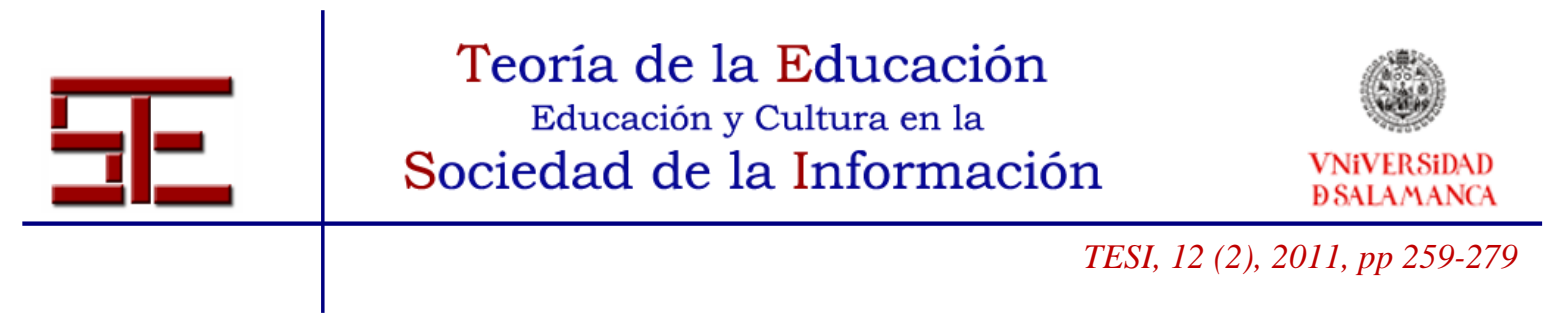

(similares a Zbrush o a Autodesk Mudbox) orientados a áreas creativas y los modeladores de caras más dirigidos a disciplinas técnicas (Tabla 4).

\begin{tabular}{|c|c|c|c|c|c|c|c|}
\hline $\begin{array}{l}\text { 응 } \\
\text { 흥 } \\
\frac{0}{0} \\
\frac{0}{0} \\
\frac{0}{2}\end{array}$ & 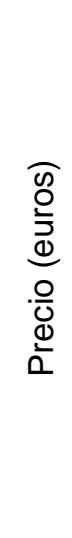 & $\begin{array}{l}\stackrel{0}{=} \\
\frac{1}{c} \\
: \frac{0}{0} \\
\frac{D}{0} \\
\stackrel{D}{>}\end{array}$ & $\begin{array}{l}\frac{}{0} \\
: \frac{0}{0} \\
\frac{0}{0} \\
0 \\
0 \\
0 \\
\frac{1}{0} \\
\frac{0}{0} \\
\frac{0}{\overline{0}} \\
\frac{0}{10} \\
0 \\
0\end{array}$ & 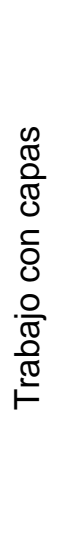 & 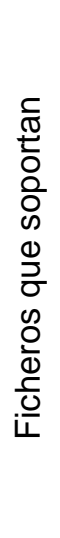 & 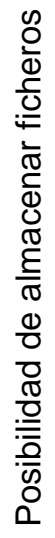 & $\begin{array}{l}\text { Comentario: } \\
\text { En todas estas aplicaciones la } \\
\text { utilización de un lápiz (stylus) mejora } \\
\text { las prestaciones por aportar mayor } \\
\text { precisión que los dedos. } \\
\text { Observaciones }\end{array}$ \\
\hline Sunn & 0,00 & - & Sí & No & - & Sí & Modelador de caras/orgánico \\
\hline $\begin{array}{r}\text { SculptM } \\
3 \mathrm{D}\end{array}$ & 2,99 & Sí & Sí & No & obj & Sí & Modelador orgánico \\
\hline IDoug & 5,49 & Sí & Sí & No & obj & Sí & Modelador orgánico \\
\hline iScultc & 3,99 & No & Sí & No & obj & Sí & $\begin{array}{l}\text { Modelador de caras con posibilidades de } \\
\text { edición de vértices, aristas y caras. }\end{array}$ \\
\hline Finger3D & 7,99 & No & Sí & No & obj & Sí & $\begin{array}{l}\text { Modelador de caras, con posibilidades de } \\
\text { edición de vértices, aristas y caras. }\end{array}$ \\
\hline
\end{tabular}

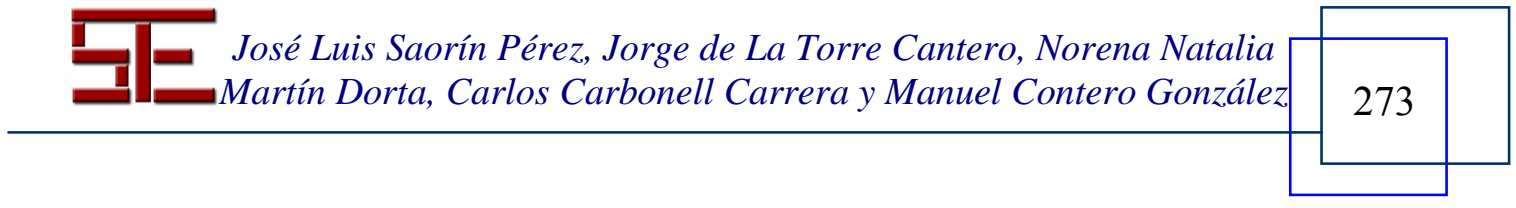




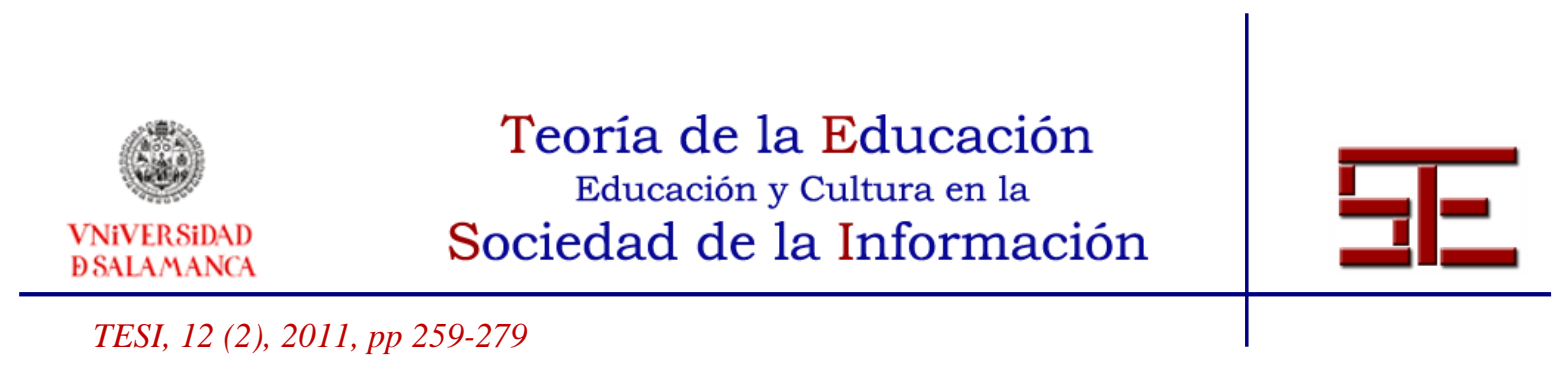

\subsection{3.- Dibujo Vectorial}

Aplicaciones similares a CorelDraw o Adobe Ilustrator que trabajan con imágenes vectoriales 2D formadas por objetos geométricos independientes (segmentos, polígonos, arcos, etc.), cada uno de ellos definido por distintos atributos matemáticos de forma, de posición, de color, etc. (Tabla 5).

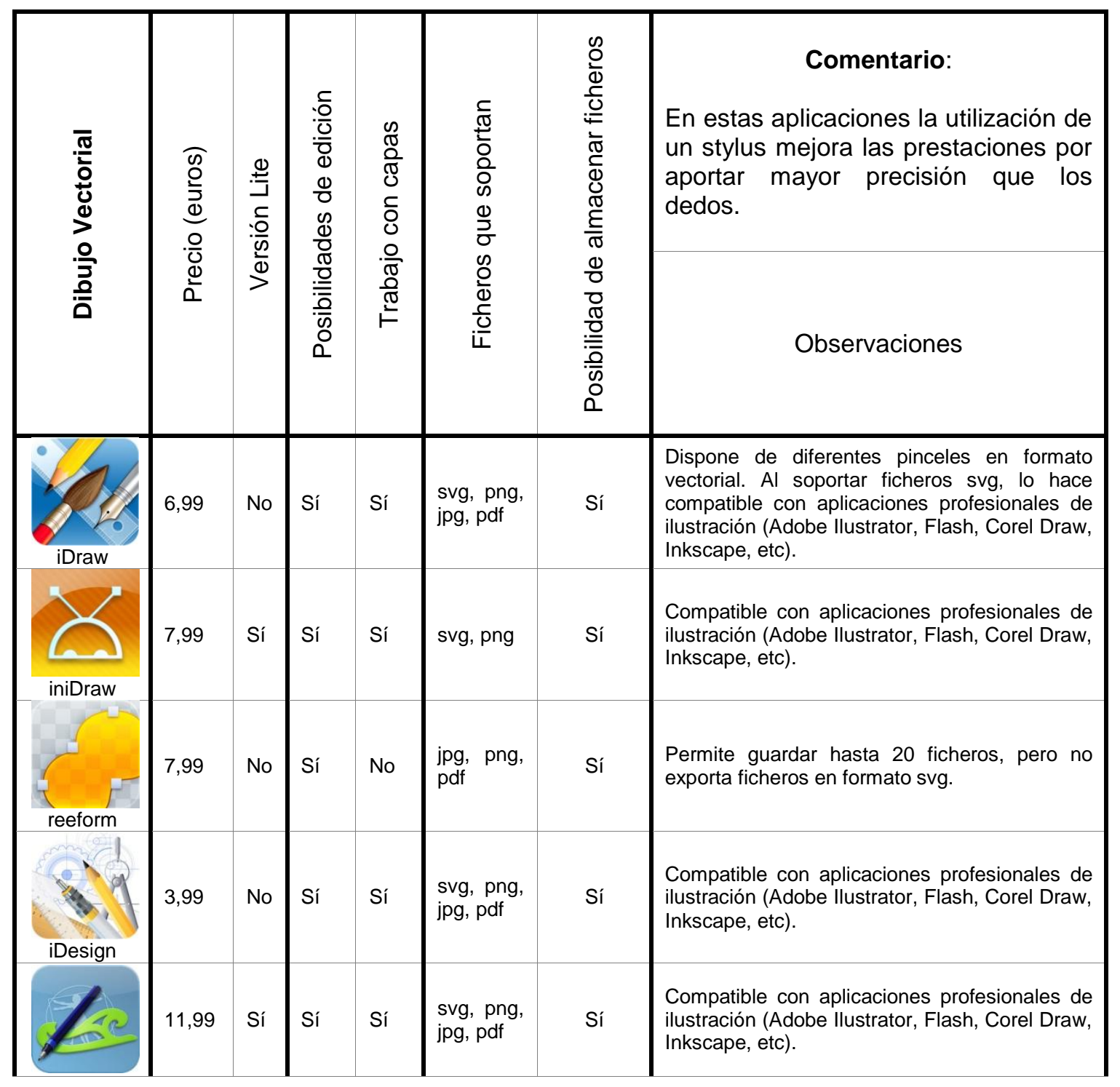

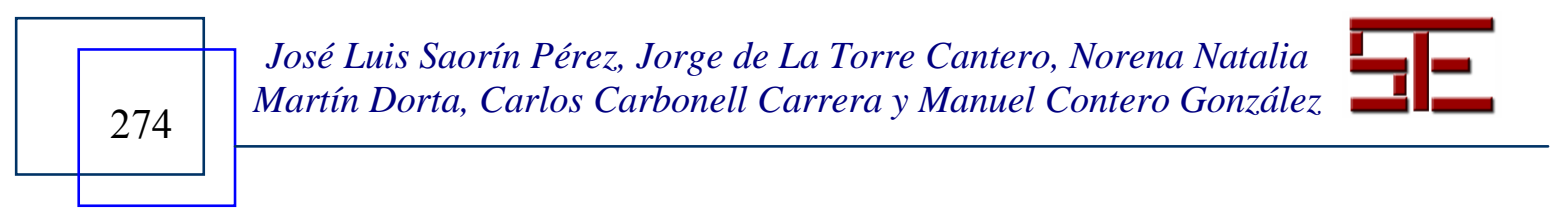



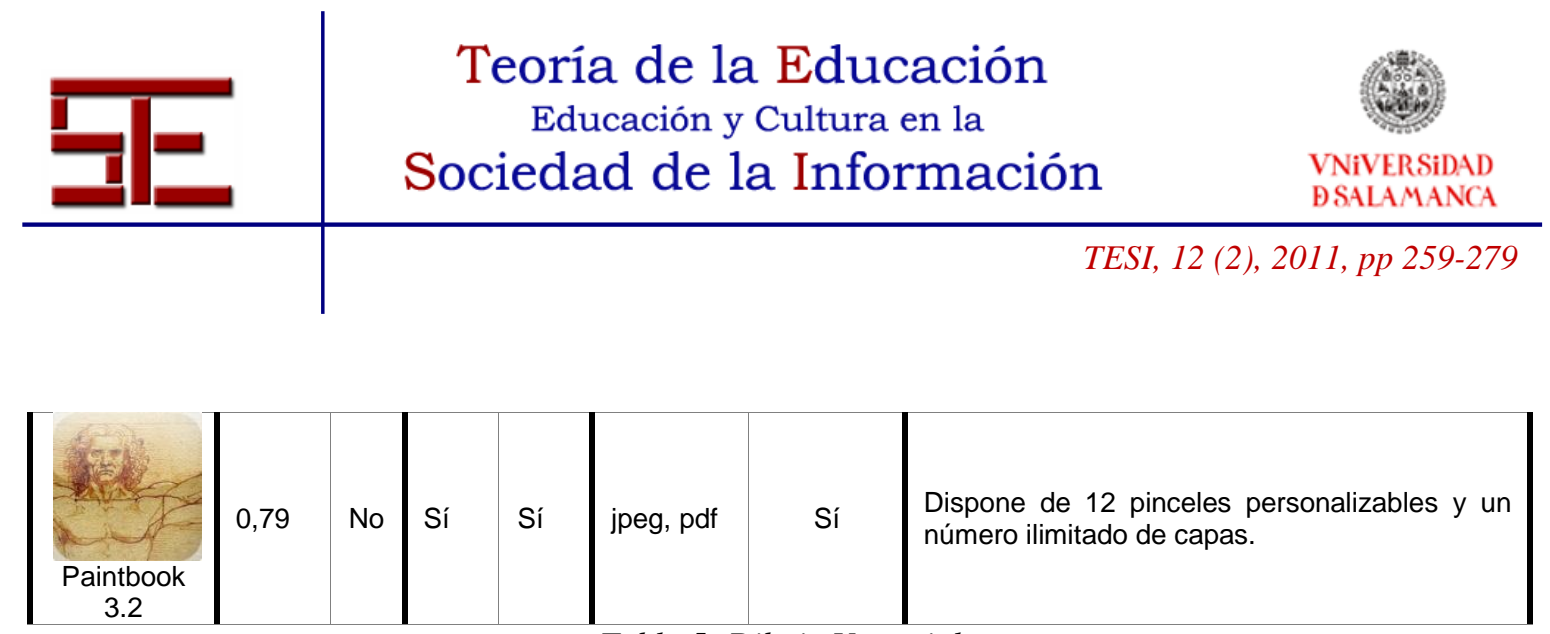

Tabla 5: Dibujo Vectorial

\subsection{3.- Dibujo Raster}

Aplicaciones que trabajan con imágenes rasterizadas, también llamadas mapas de bits, imágenes matriciales o bitmaps, a las que solemos llamar fotos y que podemos generar mediante cámaras digitales, móviles o escáneres y que mediante estas aplicaciones podremos editar de manera similar a aplicaciones tan populares como Photoshop. Existen muchas aplicaciones de esta categoría, por lo que sólo incluimos en la tabla aquellas que pensamos que ofrecen más prestaciones (Tabla 6).

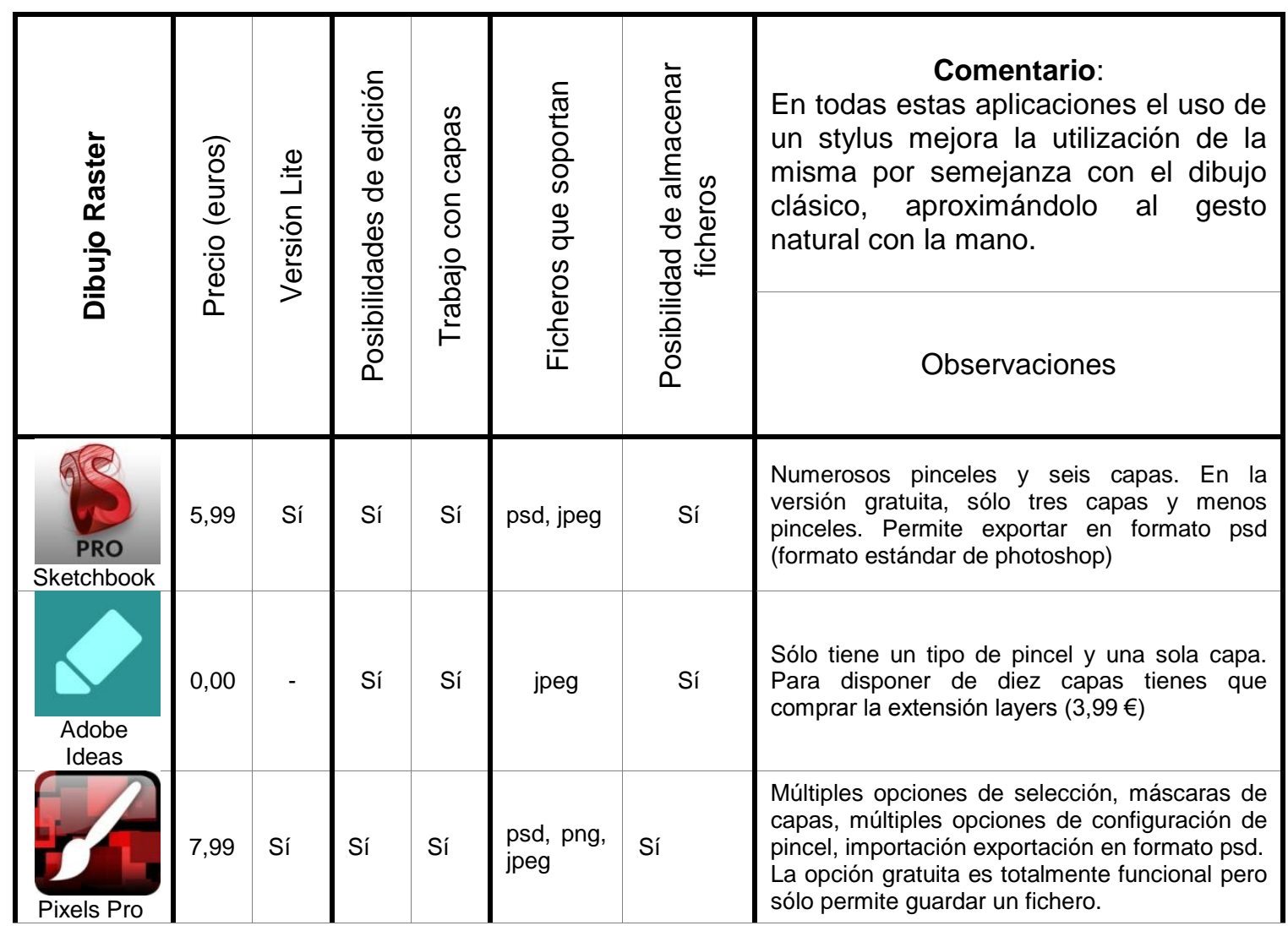

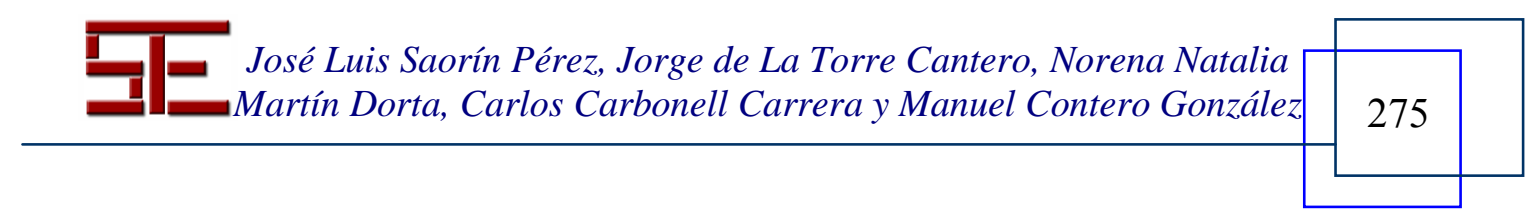




\begin{tabular}{c} 
Teoria de la Educación \\
Educación y Cultura en la \\
$\begin{array}{c}\text { VNiVERSIDAD } \\
\text { BSALAMANCA }\end{array}$ \\
\hline TESI, $12(2), 2011, p$ 2 $259-279$
\end{tabular}

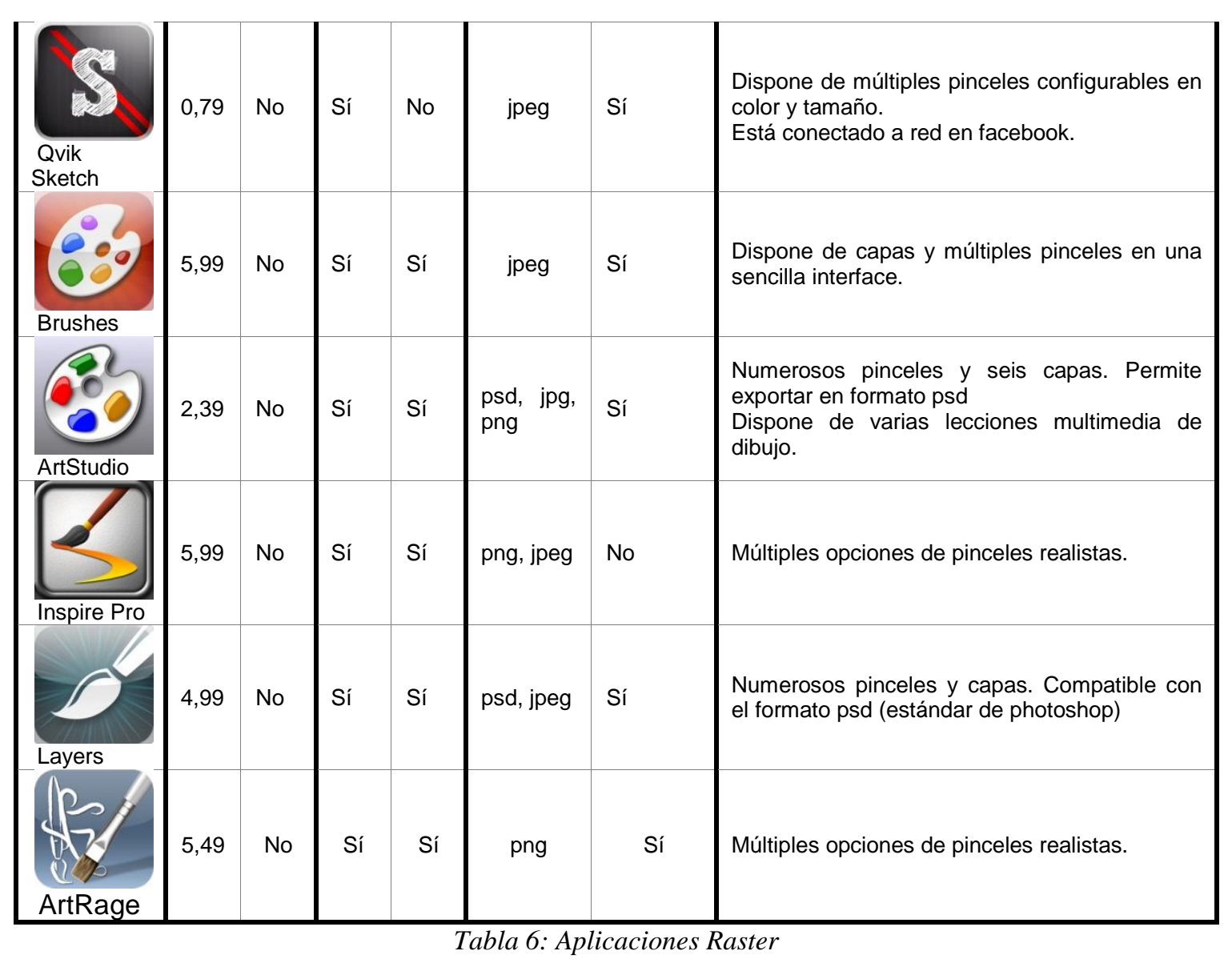

\subsection{3.- Dibujo CAD}

En este grupo contemplamos distintas aplicaciones que permiten visualizar ficheros CAD 2D/3D "tradicionales" (dxf, dwg...) y que disponen de ciertas posibilidades de edición (Tabla 7).

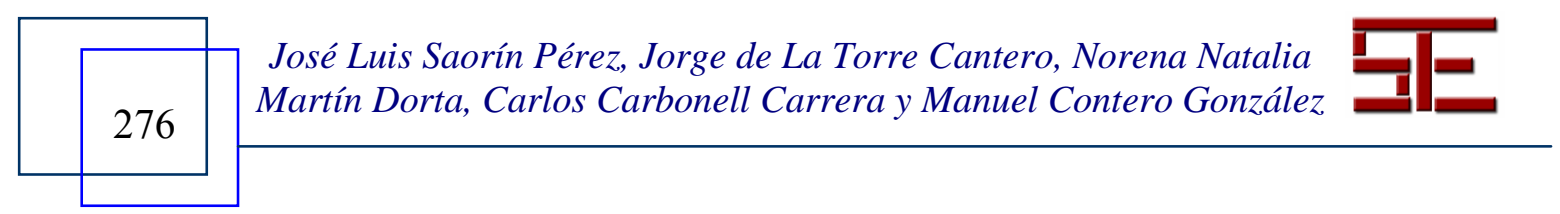




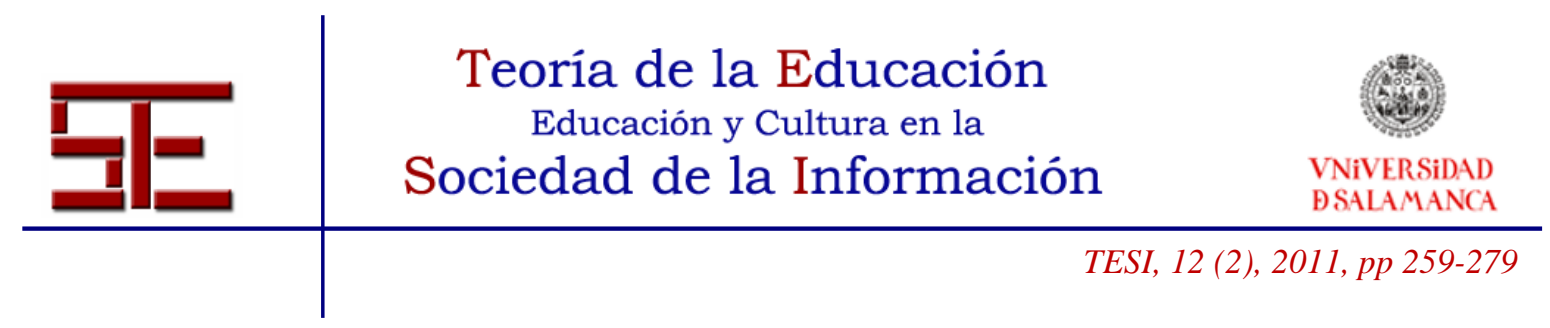

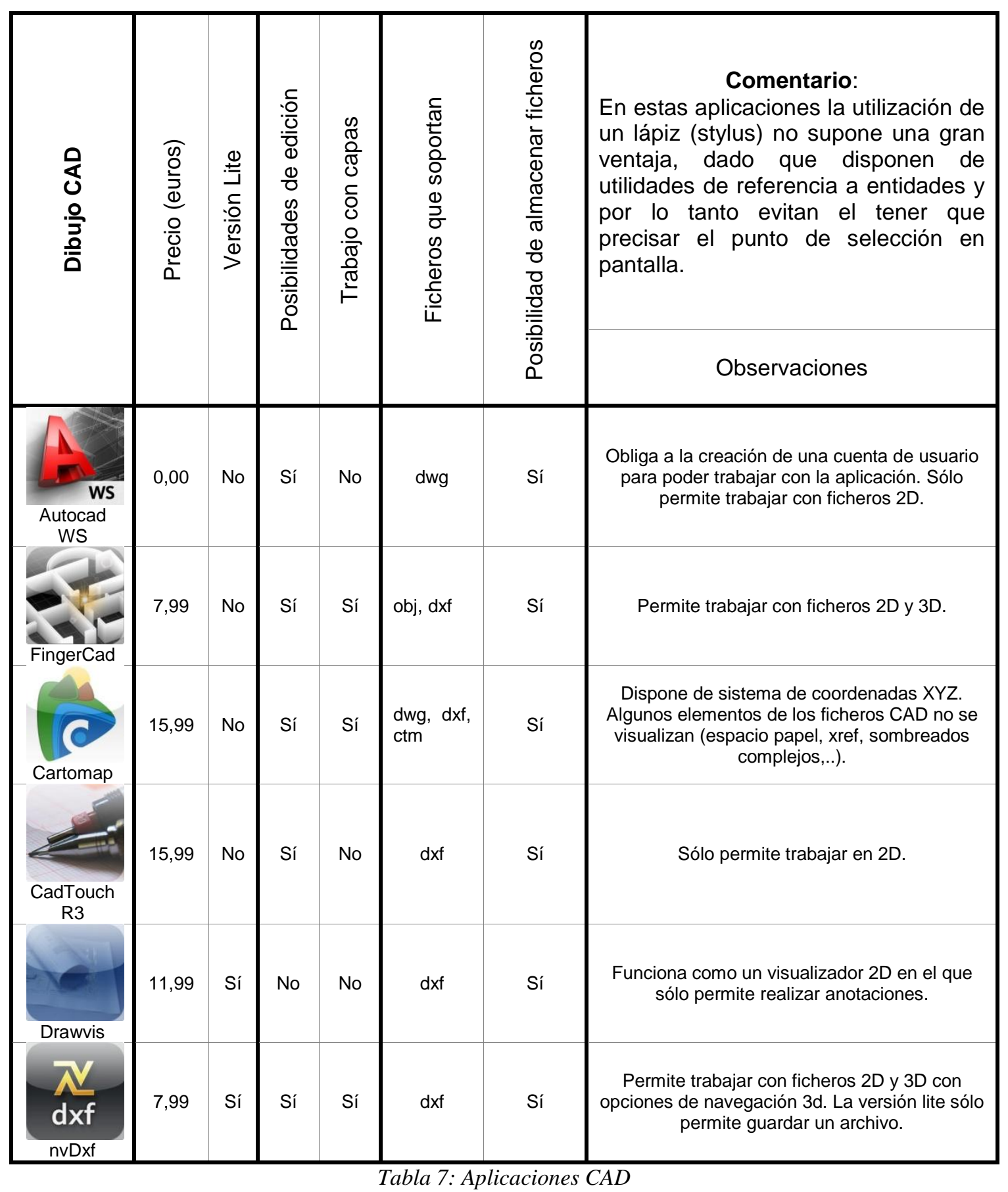

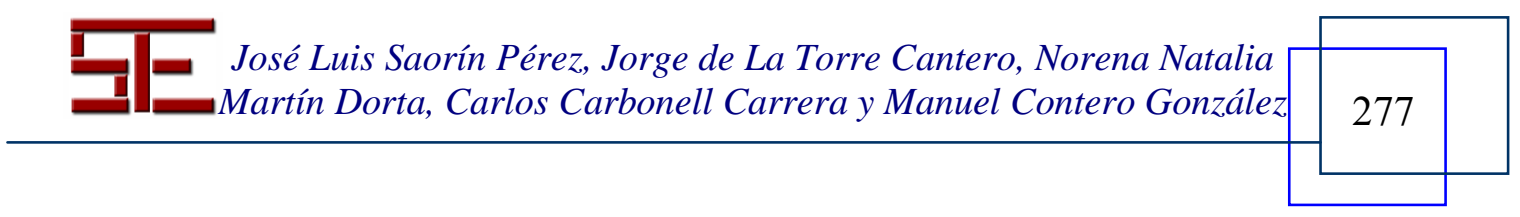




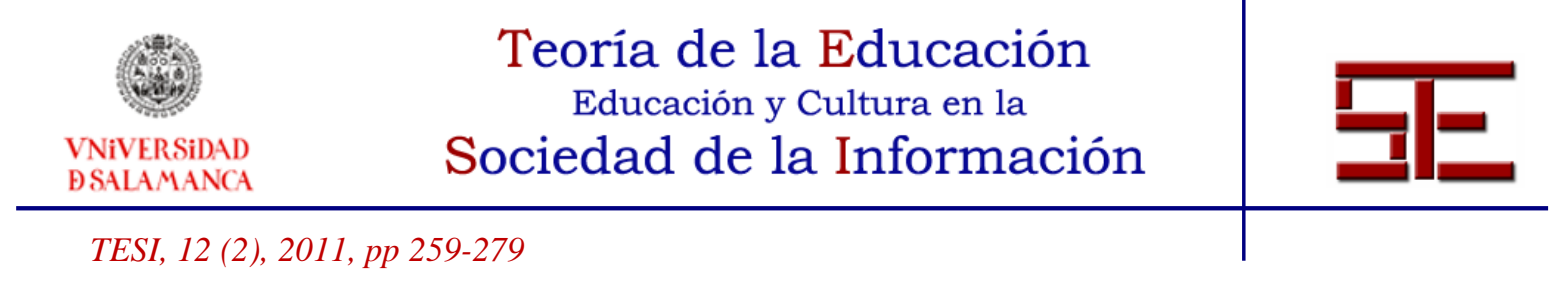

\section{4.- CONCLUSIONES}

Actualmente la mayor parte de las aplicaciones de expresión gráfica en soporte PC se están adaptando a las tabletas digitales. Esto es especialmente cierto en el caso del iPad y se espera que no tarde mucho en las tabletas que funcionen con el sistema operativo Android.

El uso de estas aplicaciones requiere una nueva forma de trabajar puesto que se manejan con gestos a los que hay que habituarse, como ya sucedió con el ratón. Sin embargo, al habituarnos a estos gestos resulta intuitivo y fácil de manejar.

El tamaño de la pantalla del iPad y la facilidad para realizar zoom la hace apropiada para su utilización en la docencia de expresión gráfica.

Como futura línea de actuación se pretende realizar talleres en centros educativos de varios niveles y en Centros de Formación de Profesores donde se pueda evaluar con contenidos específicos los resultados obtenidos por esta tableta, tanto a nivel docente, como en los aspectos de satisfacción de usuario.

También es interesante adaptar algunos de los recursos realizados por el grupo DEHAES a este nuevo formato y contrastar los resultados obtenidos.

\section{5.- BIBLIOGRAFÍA}

Area Moreira, M. (2001). Educar en la Sociedad de la Información. Bilbao: Desclée de Brouwer.

- (2007). Algunos principios para el desarrollo de buenas prácticas pedagógicas con las TICs en el aula. Comunicación y pedagogía: Nuevas tecnologías y recursos didácticos, 222, 42-47.

Austin, T. \& Doust, R. (2007). Diseño de nuevos medios de comunicación. Blume.

Chen, C. \& Chung, C. (2008). Personalized mobile English vocabulary learning system based on item response theory and learning memory cycle. Computers \& Educations, $51(2), 624-645$.

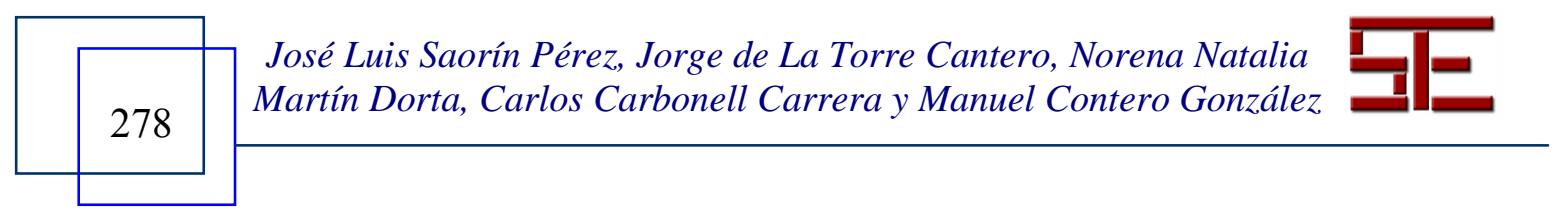




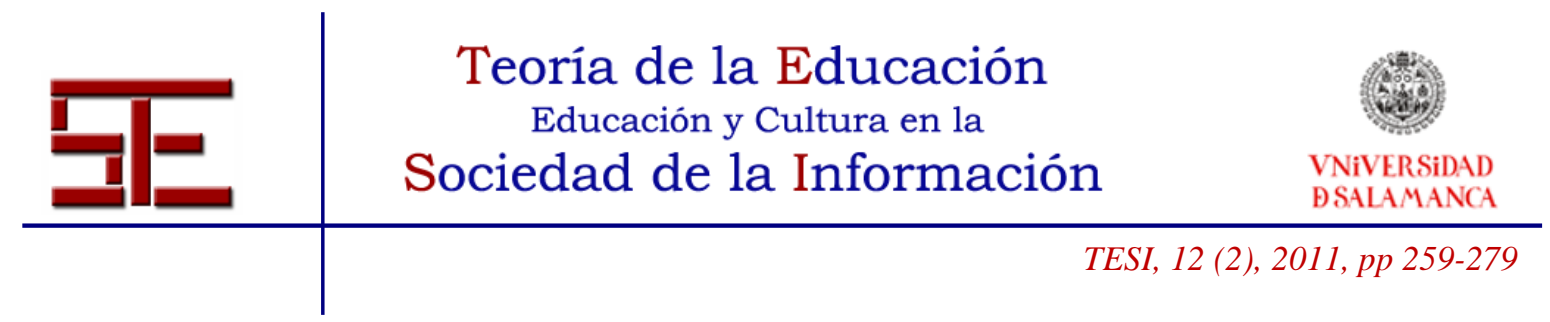

Chris, E. (2008). The effectiveness of m-learning in the form of podcast revision lectures in higher education. Computers \& Education, 50 (2), 491-498.

Gilbert, A. (2011). Los tablets acaban con el crecimiento de ventas de ordenadores. Periódico. El Economista.es. Extraído el 14 de enero, 2011 de http://www.eleconomista.es/seleccion-ee/noticias/2741029/01/11/Los-tablets-acabancon-el-crecimiento-de-ventas-de-ordenadores.html.

Imbernón, F., Silva, P. y Guzmán, C. (2011). Competencias en los procesos de enseñanza-aprendizaje virtual y semipresencial. Comunicar, 36, 107-114.

Lu, M. (2008). Effectiveness of vocabulary learning via mobile phone. Journal of Computer Assisted Learning, 24 (6), 515-525.

Martín-Dorta, N., Sánchez-Berriel, I. \& otros. (2010, septiembre). A 3D Educational Mobile Game to Enhance Student's Spatial Skills. Ponencia presentada en el 10th IEEE International Conference on Advanced Learning Technologies (ICALT), Sousse, Túnez. Martínez-Sánchez, F. (2003). Tecnología y enseñanza: una relación compleja en el nuevo siglo. Comunicar, 21, 15-21.

Sánchez, J., Salinas, A. \& Sáenz, M. (2007). Mobile game-based methodology for science learning. Human-Computer Interaction. HCI Applications and Services. Lecture Notes in Computer Science, 4553, 322-331.

Sharples, M. (2000). The Design of Personal Mobile Technologies for Lifelong Learning. Computers and Education, 34, 177-193.

Para citar el presente artículo puede utilizar la siguiente referencia:

Saorín Pérez, J. L., de La Torre Cantero, J., Martín Dorta, N. N., Carbonell Carrera, C. y Contero González., M. (2011). Tabletas digitales para la docencia del dibujo, diseño y artes plásticas, en Barrios Vicente, I. M. (Coord.) Mujeres y la sociedad de la Información. Revista Teoría de la Educación: Educación y Cultura en la Sociedad de la Información. Vol. 12, $\mathrm{n}^{\mathrm{o}}$ 2. Universidad de Salamanca, pp. 259-279 [Fecha de consulta: $\mathrm{dd} / \mathrm{mm} / \mathrm{aaaa}]$.

http://campus.usal.es/ revistas_trabajo/index.php/revistatesi/article/view/8281/8285

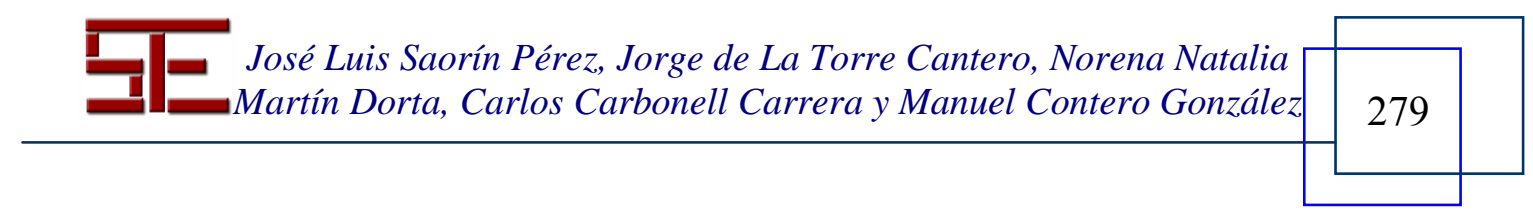

